In this study, a mathematical integrated model is developed to investigate the wave-induced sloping seabed response in the vicinity of breakwater. In the present model, the wave model is based on the Volume-Averaged/Reynolds Averaged Navier-Stokes (VARANS) equations, while Biot's consolidation equation is used to govern the soil model. The influence of turbulence fluctuations on the mean flow with respect to the complicated interaction between wave, sloping seabed and breakwater are obtained by solving the Volumed-Averaged $k-\epsilon$ model. Unlike previous investigations, the phase-resolved absolute shear stress is used as the source of accumulation of residual pore pressure, which can link the oscillatory and residual mechanisms simultaneously. Based on the proposed model, parametric studies regarding the effects of wave and soil characteristics as well as bed slopes on the wave-induced soil response in the vicinity of breakwater are investigated. Numerical results indicate that wave-induced seabed instability is more likely to occur in a steep slope in the case of soil with low relative density and low permeability under large wave loadings. It is also found that, the permeability of breakwater significantly affect the potential for liquefaction, especially in the region below the breakwater.

\section{Numerical study of wave-induced soil response in a sloping seabed in the vicinity of a breakwater}

\author{
H-Y Zhao, D-S Jeng* \\ Griffith School of Engineering, Griffith University Gold Coast Campus, Australia, QLD
}

\begin{abstract}
Keywords: Sloping seabed; breakwater; VARANS equation; poro-elastic; pre-consolidation;
\end{abstract}
phase-resolved shear stress; liquefaction.

\section{Introduction}

The phenomenon of seabed stability around marine infrastructures such as pipelines, breakwaters, seawalls and offshore wind turbine foundations has attracted great attentions among coastal geotechnical engineers, due to growing activities in marine environments. In natural ocean environments, the pore pressures within the seabed may become excessive when it cannot dissipate as fast as the water waves propagation over a porous seabed. With the excess pore 
pressure and accompanying decreases in effective stress, part of seabed may become unstable or even liquefied. The wave-induced liquefaction has been identified as one of main processes in the analysis of seabed instability around marine installations [1]. Thus, the evaluation of wave-induced pore pressures and effective stresses are important for coastal engineers involved in the design of foundation for breakwaters.

Based on the observations in laboratory experiments and field measurements, two mechanisms for the wave-induced liquefaction in sandy bed have been identified: transient or momentary liquefaction and residual liquefaction $[2,3]$. The transient liquefaction most generally occurs within unsaturated marine soils under wave troughs when there is an upward seepage force due to the dissipation of pore pressure induced by the encapsulated air $[4,5,6]$. On the other hand, the residual liquefaction is normally seen in fully saturated seabed due to the build-up of excess pore pressure caused by the volumetric contraction under the action of cyclic loading $[7,8,9]$.

Adopting the poro-elastic theory [10], there have been various analytical investigations of the problem for wave-seabed interaction, including $[4,5,11]$, in which an elastic soil skeleton and a Darcy's flow with compressible pore water are coupled together. In these investigations, there was no any marine structure on seabed, and the linear and nonlinear Stokes waves were used to apply dynamic force on seabed surface. Later, this framework has been further applied in the analysis of the wave induced seabed response in the vicinity of a vertical seawall $[6$, $12,13,14,15]$, in which the boundary conditions are simple with simplified configuration of breakwaters.

Besides the development of analytical solutions, numerical methods have been widely applied in the analysis of seabed response with a structure. Among these Mase et al. [16] developed a two-dimensional finite element model to investigate the wave-induced pore pressures and effective stresses in a sandy seabed as well as those in a rubble mound foundation of a composite caisson-type breakwater subject to linear standing wave. In their analysis, the lateral boundary conditions are provided by the analytical solution proposed by Yamamoto et al. [5]. Jeng et al. [17] further investigated the effect of wave and soil characteristics on the wave-induced soil response near the composite breakwater located at a finite, isotropic and homogeneous seabed. Mizutani and Mostafa [18] and Mostafa et al. [19] developed a BEM-FEM 
combination numerical model to investigate the interaction of wave-seabed-breakwater. In their models, the Laplaces equation for fluid domain and the modified Navier-Stokes equation for the porous flow in seabed and rubble mound are solved using BEM while the determination of stress status in seabed foundation are obtained by solving the Biots consolidation using FEM. Ulker et al. [20] may be the first to consider the effect of pre-consolidation due to the selfweight of a composite breakwater in the assessment of the momentary liquefaction subject to standing wave loading. Their research concluded that there was always a liquefaction zone at the toe of the rubble-mound foundation, which would directly result in the instability of the breakwater. However, the wave models in all aforementioned numerical models are based on the potential flow theory, which is incapable of capturing complicated wave motion (i.e., wave breaking, turbulence fluctuations).

Recently, some numerical models were further developed to overcome the disadvantage mentioned above by combing the Reynolds-Averaged Navier-Stokes equations (RANS) for wave field and the Volume-Averaged Reynolds-Averaged Navier-Stokes (VARANS) equations for the porous flow in a porous medium in which the flow field in the whole computational domain, and the flux at the interface between the porous seabed/marine structures and the seawater, are all continuous $[21,22,23,24,25,26]$. However, the wave-induced pore pressure and effective stress changes within the seabed have not been concerned in these models. Later, Jeng et al. [27] developed an integrated model (PORO-WSSI 2D) for the problem of wave-seabed-structure interaction, in which the Volume-Averaged Reynolds Averaged Navier-Stokes (VARANS) equations are used to govern the wave motion and porous flow in seabed/breakwater, the dynamic Biots equations are used to govern the behaviors of porous seabed and marine structures. Due to the fact that the VARANS equations are adopted in PORO-WSSI II, the complicated wave motion can be simulated [28].

There are some laboratory experiments for the wave-induced pore pressure build-up mechanism in the literature $[29,30]$. Based on laboratory tests [30], it has been recognized that the pore pressure accumulation is mainly related to the cyclic shear stress ratio, the period of cyclic loading and the cyclic loading number required to reach the residual liquefaction value. Seed and Rahman [7] may be the first to investigate a simple 1-D finite element model to describe the build-up of pore pressure under progressive wave. This model has been further 
extended or modified to examine the wave-induced residual response analytically and numerically [31, 8, 32, 33]. Sassa and Sekiguchi [34] developed a 2-D elasto-plastic constitutive model where the principal stress axes rotation in the sand is incoporated and compared the numerical solutions with their experimental measurements conducted in a centrifuge wave tank [35]. Regarding the build-up mechanism for the wave-seabed-structure interactions, Li and Jeng [36] proposed a 3D analytical solution to investigate wave-induced soil response around breakwater heads, including both oscillatory and residual mechanisms. Later, a more sophisticated constitutive elaso-plastic model for determining the dynamic response and residual liquefaction potential around breakwater head was investigated by Jeng and Ou [37]. In both of their analysis, the breakwaters are simplified as a line without width and weight. And the effects of configuration of structure on the wave field and the structure weight on the stress field on the seabed foundation are totally neglected.

All aforementioned studies have only concerned a breakwater built on a flat seabed foundation. A few research has been done for the interaction between wave, sloping seabed and breakwater, but limited to the oscillatory mechanism in seabed foundation or rubble mound breakwaters [38, 39]. Among these, Ye et al. [38] considered the case with tsunami loading, while Ye et al. [39] considered the case with breaking waves. However, all these investigations were limited to oscillatory mechanisms, rather than residual mechanisms. In reality, the wave-induced pore pressure accumulation accompany with the residual liquefaction in seabed is much easier to occur than the oscillatory pore pressure and momentary liquefaction in engineering practice.

In this study, the wave model is based on the VARANS equation, in which the turbulence fluctuations due to the interaction between wave, slope seabed and breakwater are obtained by solving the volume-averaged $\mathrm{k}-\epsilon$ model. In addition to the wave model, another new feature of this paper is the new definition of residual mechanism of porous seabed model, in which the source term is determined by the phase-resolved shear stress rather than the shear stress amplitude over wave period used in previous studies $[8,32,36]$. As the phase-resolved shear stress is related to the oscillatory mechanism of soil response, both the wave-induced oscillatory mechanisms and residual mechanisms around a breakwater will be discussed. Regarding the liquefaction, we will focus on the wave-induced residual liquefaction. 


\section{Theoretical formulations}

The computational domain and dimension sizes are shown in Fig. 2. An impermeable rubble mound breakwater is constructed on a sloped seabed (gradient angle 1:50). The internal wave maker is placed over flat part of seabed foundation. In this study, the fifth-order stokes wave theory was used to generated the incident waves. The oscillatory and residual mechanisms of seabed response are modelled by a poro-elastic model. Both wave and seabed models are integrated into a single model.

\subsection{Seabed model}

In general, two mechanisms for the wave-induced soil response have been observed in field measurements and laboratory experiments [2], as shown in Fig. 1, which can be expressed as

$$
b=\tilde{b}+\bar{b}, \text { where } \bar{b}=\frac{1}{T} \int b d t
$$

where $T$ is the wave period, $b$ denotes the the wave-induced soil response variables (including soil displacements, stresses and pore pressures), $\tilde{b}$ represents the oscillatory component, $\bar{b}$ represents the residual component. In the following sections, both components will be considered.

\subsubsection{Oscillatory soil response}

In this study, we considered a saturated porous seabed hydraulically isotropic with the same permeability $K$ in all directions, with ignoring of the geometric nonlinearities (small-strain assumption). Then, the conservation of mass leads to

$$
\nabla^{2} \tilde{p}-\frac{\gamma_{w} n_{s} \beta_{s}}{K} \frac{\partial \tilde{p}_{s}}{\partial t}=\frac{\gamma_{w}}{K} \frac{\partial}{\partial t}\left(\frac{\partial \tilde{u}_{s}}{\partial x}+\frac{\partial \tilde{w}_{s}}{\partial z}\right)
$$

in which $\tilde{p}$ is wave-induced oscillatory pore pressure, $n_{s}$ is the soil porosity, $\gamma_{w}$ is the unit weight of pore water, and $\beta_{s}$ is the compressibility of pore fluid, which is defined by

$$
\beta_{s}=\frac{1}{K_{w}}+\frac{1-S}{P_{w 0}}
$$


where $K_{w}$ is the true modulus of elasticity of water (taken as $2 \times 10^{9} \mathrm{~N} / \mathrm{m}^{2}$ ), $P_{w o}$ is the absolute water pressure, and $S$ is the degree of saturation.

With quasi-static soil behavior [10], the governing equations for the force equilibrium in the soil can be written as

$$
\begin{aligned}
& G \nabla^{2} u_{s}+\frac{G}{1-2 \mu_{s}} \frac{\partial}{\partial x}\left(\frac{\partial u_{s}}{\partial x}+\frac{\partial w_{s}}{\partial z}\right)=\frac{\partial p_{s}}{\partial x}, \\
& G \nabla^{2} w_{s}+\frac{G}{1-2 \mu_{s}} \frac{\partial}{\partial z}\left(\frac{\partial u_{s}}{\partial x}+\frac{\partial w_{s}}{\partial z}\right)=\frac{\partial p_{s}}{\partial z},
\end{aligned}
$$

in which $\nabla^{2}$ is the Laplace operator, $G$ is shear modulus of soil, which is related to Young's modulus $(E)$ and Poisson's ratio $\left(\mu_{s}\right)$ as $E / 2\left(1+\mu_{s}\right) ;\left(u_{s}, w_{s}\right)$ are the soil displacements in the $x$ - and $z$-directions, respectively; $p_{s}$ is pore pressure, $\mu_{s}$ is Poisson's ratio;

\subsubsection{Residual soil response}

The inelastic volumetric contraction for loose sand under cyclic loading may lead to a gradual increase in residual pore pressures. Based on the mechanism of wave-induced residual pore pressure accumulation proposed by [7], the residual pore pressure can be derived from 1-D Biot's consolidation equation [8,32], which can be further extended to 2-D case with the following governing equation,

$$
\frac{\partial \bar{p}}{\partial t}=c_{v}\left(\frac{\partial^{2} \bar{p}}{\partial x^{2}}+\frac{\partial^{2} \bar{p}}{\partial z^{2}}\right)+f(x, z, t)
$$

where $\bar{p}_{s}$ denote the wave-induced residual pore pressure, and $c_{v}$ is coefficient of consolidation based on plain strain which can be defined as

$$
c_{v}=\frac{G K}{\gamma_{w}(1-2 \mu)} \text {. }
$$

It should be noted that the source term in Eq. (6) are re-defined as a 2-D time-dependent function in which the phase-resolved absolute shear stress are considered as the source of pore pressure generation, 


$$
f(t)=\frac{\sigma_{0}^{\prime}}{T}\left[\frac{\left|\tilde{\tau}_{i n s}(x, z, t)\right|}{\alpha_{r} \sigma_{0}^{\prime}}\right]^{-\frac{1}{\beta_{r}}},
$$

in which $\left|\tilde{\tau}_{\text {ins }}(x, z, t)\right|$ is the absolute value of phase-resolved oscillatory shear stress, and $\alpha_{r}$ and $\beta_{r}$ are two empirical coefficients which can be estimated by the empirical expressions [40]: $\alpha_{r}=0.34 D_{r}+0.084$ and $\beta_{r}=0.37 D_{r}-0.46$.

In addition to the new 2-D definition of source term, we consider the effect of weight of breakwater on the initial consolidation status. Then, the effective normal stresses $\left(\sigma_{0}^{\prime}\right)$ can be expressed as

$$
\sigma_{0}^{\prime}=\frac{1+\mu_{s}}{3}\left(\sigma_{s z}^{\prime}+\sigma_{s x}^{\prime}\right)
$$

where $\sigma_{s x}^{\prime}$ and $\sigma_{s z}^{\prime}$ are the initial effective stress in the $x$ - and $z$-directions, respectively, which can be obtained based on Hooke's law from the present model subject to static loadings.

\subsection{Wave model}

The VARANS (Volume-Averaged Reynolds Averaged Navier-Stokes) which are derived by applying a volume-averaging operator over a representative elementary volume to the NavierStokes equations can be expressed as:

$$
\begin{aligned}
\frac{\partial\left\langle\bar{u}_{f i}\right\rangle}{\partial x_{i}}=0, & \\
\frac{\partial\left\langle\bar{u}_{f i}\right\rangle}{\partial t}+\frac{\partial\left\langle\bar{u}_{f j}\right\rangle}{n\left(1+c_{A}\right)} \frac{\partial\left\langle\bar{u}_{f i}\right\rangle}{\partial x_{j}}= & \frac{1}{1+c_{A}}\left[-\frac{n}{\rho_{f}} \frac{\partial\langle\bar{p}\rangle^{f}}{\partial x_{i}} \frac{\partial\left\langle\overline{u_{f i}^{\prime} u_{f j}^{\prime}}\right\rangle}{\partial x_{j}}+\frac{1}{\rho_{f}} \frac{\partial\left\langle\bar{\tau}_{f i j}\right\rangle}{\partial x_{j}}+n g_{i}\right] \\
& -\frac{\left\langle\bar{u}_{f i}\right\rangle}{1+c_{A}}\left[\frac{\alpha_{f}^{\prime}(1-n)^{2}}{n^{2} d_{50}^{2}} \frac{\beta_{f}(1-n)}{n^{2} d_{50}} \sqrt{\left\langle\bar{u}_{f 1}\right\rangle^{2}+\left\langle\bar{u}_{f 2}\right\rangle^{2}}\right]
\end{aligned}
$$

in which $u_{f i}$ is the flow velocity, $x_{i}$ is Cartesian coordinate, $t$ is the time, $\rho_{f}$ is the density of fluid, $p$ is the pressure, $g_{i}$ is the acceleration due to gravity, $n$ and $d_{50}$ are the porosity and equivalent mean diameter of the porous material respectively. 
In Eq. (11), $c_{A}$ denotes the added mass coefficient, calculated by $c_{A}=0.34(1-n) n . \alpha_{f}^{\prime}=200$ and $\beta_{f}=1.1$ are empirical coefficients associated with the linear and nonlinear drag force respectively. $\alpha$ and $\beta$ are empirical coefficients through the fitting and regression of a wide range of experiment data, Liu et al. [25] suggested that the $\alpha=200$ and $\beta=1.1$ for porous flow. Recently, Lara et al. [24] recommends two nonlinear relations relating the empirical coefficients $\alpha$ and $\beta$ to the porosity $n$ and mean particle size $d_{50}: \alpha=4409.22 d_{50}, \beta=12.27 \frac{n^{3}}{(1-n)^{1.5}} d_{50}^{-0.1075}$. The viscous stress tensor of mean flow $\left(\tau_{f i j}\right)$, can be defined as:

$$
\tau_{f i j}=v_{f}\left(\frac{\partial \bar{u}_{f i}}{\partial x_{j}}+\frac{\partial \bar{u}_{f j}}{\partial x_{i}}\right)
$$

where $v_{f}$ is the molecular viscosity. The over-bar represents the ensemble average in the case of waves and the prime denotes turbulent fluctuations induced by the ensemble mean. It should be noted here that since the VARANS equations are also valid for steady or noncyclic unsteady flow scenarios, in this case, the over-bar denote time averaging rather than ensemble averaging. The symbol \langle\rangle and \langle\rangle$^{f}$ stand for Darcy's volume averaging operator and the intrinsic averaging operator, respectively, and can be defined as:

$$
\langle a\rangle=\frac{1}{\forall} \int_{\forall_{f}} a d \forall, \text { and }\langle a\rangle^{f}=\frac{1}{\forall^{f}} \int_{\forall_{f}} a d \forall
$$

in which $\forall$ is the total averaging volume, and $\forall_{f}$ is the portion of $\forall$ that is occupied by the fluid. The relationship between the Darcy's volume averaging operator and intrinsic volume averaging is $\langle a\rangle=n\langle a\rangle^{f}$.

The influence of turbulence fluctuations on the mean flow, denoted as $\left\langle u_{f i}^{\prime} u_{f j}^{\prime}\right\rangle$, is obtained by solving the volume-averaged $k-\epsilon_{f}$ equations shown as

$$
\begin{aligned}
\frac{\partial\langle k\rangle}{\partial t}+ & \frac{\partial\left\langle\bar{u}_{f j}\right\rangle}{n} \frac{\partial\langle k\rangle}{\partial x_{j}}+\frac{\partial\left\langle\bar{u}_{f j}\right\rangle}{n} \frac{\partial\langle k\rangle}{\partial x_{j}}=-\frac{\left\langle\overline{u_{f i}^{\prime} u_{f j}^{\prime}}\right\rangle}{n} \frac{\partial\left\langle\bar{u}_{f i}\right\rangle}{\partial x_{j}} \\
+ & \frac{\partial}{\partial x_{j}}\left[\left(\frac{\partial\left\langle v_{e t}\right\rangle}{\sigma_{k}}+v_{e}\right) \frac{\partial k}{\partial x_{j}}\right]-\left\langle\epsilon_{f}\right\rangle+n \epsilon_{f \infty} \\
\frac{\partial\left\langle\epsilon_{f}\right\rangle}{\partial t}+ & \frac{\partial\left\langle\bar{u}_{f j}\right\rangle}{n} \frac{\partial\left\langle\epsilon_{f}\right\rangle}{\partial x_{j}}=\frac{\partial}{\partial x_{j}}\left[\left(\frac{\partial\left\langle v_{e t}\right\rangle}{\sigma_{\epsilon}}+v_{e}\right) \frac{\partial \epsilon}{\partial x_{j}}\right] \\
& -C_{1 \epsilon} \frac{\langle\epsilon\rangle}{n\langle k\rangle} \overline{\left\langle u_{f i}^{\prime} u_{f j}^{\prime}\right\rangle} \frac{\partial\left\langle\bar{u}_{f j}\right\rangle}{\partial x_{j}}-C_{2 \epsilon} \frac{\left\langle\epsilon_{f}\right\rangle^{2}}{\langle k\rangle}+n C_{2 \epsilon} \frac{\epsilon_{f \infty}^{2}}{k_{\infty}}
\end{aligned}
$$


where $v_{e t}$ is the eddy viscosity and $v_{e}$ is the dynamic viscosity which can be expressed as $v_{f} / \rho_{f}$. The empirical coefficients $C_{1 \epsilon}, C_{2 \epsilon}, \sigma_{\epsilon}$ and $\sigma_{k}$ are 1.44, 1.92, 1.3 and 1.0, respectively, which are estimated from stationary flows experiment [41]. The $\epsilon_{f \infty}$ and $k_{\infty}$ can be defined as

$$
\begin{aligned}
& \epsilon_{f \infty}=39.0 \frac{(1-n)^{2.5}}{n}\left(\left\langle\overline{u_{1}}\right\rangle^{2}+\left\langle\overline{u_{2}}\right\rangle^{2}\right)^{1.5} \frac{1}{d_{50}} \\
& k_{\infty}=3.7 \frac{1-n}{\sqrt{n}}\left(\left\langle\overline{u_{1}}\right\rangle^{2}+\left\langle\overline{u_{2}}\right\rangle^{2}\right)
\end{aligned}
$$

\subsection{Boundary conditions}

Regarding the mean flow field, the no-slip boundary condition is imposed on the seafloor surface and breakwater surface $\left(u_{f i}=0\right)$. The zero-stress condition is adopted on the mean free surface $\left(\tau_{f i j}=0\right)$, while the effect of air flow is neglected. For the turbulence field, the log-law distribution of mean tangential velocity in the turbulent boundary layer is imposed in the rigid point next to seafloor. Both the turbulent kinetic energy $(k)$ and its dissipation rate $\left(\epsilon_{f}\right)$ on the

free surface are implemented with zero gradient boundary conditions, (i.e. $\frac{\partial k}{\partial n}=\frac{\partial \epsilon_{f}}{\partial n}=0$, in which $n$ is the unit normal on the free surface). The damping zone located at two vertical boundaries which are far from the concerned region. To avoid the simultaneous specification of wave and current at inflow boundary, the internal wave-maker method by adding a source function $S\left(x_{i}, t\right)$ into the mass conservation equation [42] is used in the present study. An absorption function is implemented on the right boundary which is placed far enough from the region of interest. Thus the error induced by the reflecting waves can be neglected.

At the seabed surface, the vertical effective normal stress vanishes and the oscillatory pore pressure is equal to the wave pressure obtained from the wave model, while the residual pore pressure are assumed as zero at the surface of the seabed $(z=0)$,

$$
\tilde{p}_{s}(x, 0 ; t)=P_{w}(x, t), \quad \tilde{\tau}_{s}(x, 0 ; t)=\tau_{f}(x, t), \quad \tilde{\sigma}_{s z}^{\prime}=0, \quad \bar{p}_{s}=0,
$$

For the soil resting on an impermeable rigid bottom, zero displacements and no vertical flow occurs at the bottom of the seabed $(z=-h)$, then we have 


$$
\frac{\partial \tilde{p}_{s}}{\partial z}=0, \quad \frac{\partial \bar{p}_{s}}{\partial z}=0, \quad \tilde{u}_{s}=\tilde{w}_{s}=0
$$

It is assumed that no relative displacement occurs at the interface between the breakwater and seabed foundation where no vertical flux flow occur in the case of impermeable breakwater.

Both lateral boundaries of seabed are fixed. The distance from the breakwater to the left and right lateral side of seabed is $250 \mathrm{~m}$ and $300 \mathrm{~m}$, respectively. These distances are sufficient to eliminate the effect of lateral boundary condition on the stress field in the region of interest, as reported in [43].

\subsection{Integration of wave and seabed models}

In this study, it is assumed that the poro-elastic deformations of seabed are small and do not affect the wave elevation on the sea floor. There are three main steps in the semi-coupling process. The mechanisms of the interaction between wave, slope seabed and a breakwater including the water elevation, velocity field and wave pressures are solved in the wave model first. The free surface locations are tracked by the volume of fluid data on the mesh. The expected wave train is generated by using a method of mass source function. Since fluid velocity and flux have little effect on the dynamic response of seabed foundation [44], only the wave pressure along seabed surface are extracted from the wave model, which will be applied as a dynamic boundary condition for the seabed model. Thirdly, the seabed model is solved to obtain oscillatory seabed response, including pore water pressure, soil displacement and effective shear stress. Then, the oscillatory shear stresses will be included in the source term and the residual soil response will be determined through Eq. (6). The seabed model was developed by using finite element software [45].

To accurately simulate the wave-seabed-breakwater interactions, the time interval for both the fluid domain and solid domain is usually set as a very small value, for example, $T / 100$, where $\mathrm{T}$ is the wave period. Orthogonal grid is used in the fluid domain, the size of which in the $x$ - direction is $0.35-0.5 \mathrm{~m}$; it is $0.1-0.2 \mathrm{~m}$ in $z$ - direction. In the solid domain, non-orthogonal FEM mesh which totally contains 27680 elements is used. For both fluid and solid domain, dense mesh size is used in the region close to the breakwater. The input data for computation is tabulated in Table 1. 


\subsection{Verifications}

The first verification of the present model is for oscillatory pore pressures. The numerical results of the maximum vertical oscillatory pore pressure $\left(|\tilde{p}| / p_{0}, p_{0}\right.$ is the amplitude of dynamic wave pressures at the seabed surface) versus relative soil depth $(z / h)$ are compared with analytical solutions [6] and laboratory experiments [46]. Based on the poro-elastic theory developed by Biot [10], Hsu and Jeng [6] developed an analytical solution for an unsaturated, anisotropic soil of finite thickness. The case of a saturated, isotropic soil subject to a progressive wave loading is used for the validation of the wave-induced oscillatory pore pressure in a porous seabed without a structure in this study. Recently, Liu and Jeng [46] conducted a series of 1-D laboratory experiments to investigate the vertical profile of pore pressure distributions in marine sediments. The one-dimensional facility in their experiments was set-up with a vertical cylinder, a $1.8 \mathrm{~m}$ soil layer and $0.2 \mathrm{~m}$ water above the deposit which is an improvement on the basis of the one originally designed by Zen and Yamazaki [2]. Unlike [2], an additional static loading was applied on top of dynamic loading. This allows the facility to simulate the case with large waves which is close to the natural ocean environments. More details of the experiments are available in [46]. As shown in Fig. 3, the present model overall agrees with the analytical solution and slightly different from the laboratory experiments.

Another possible verification of the present model is through the simplicity of this model to the flat seabed foundation without a breakwater. The wave-induced residual pore pressure from the present model are validated against experimental data from [40]. The input data are given here: wave period $(T)=1.6 \mathrm{sec}$; wave height $(H)=0.18 \mathrm{~m}$; water depth $(d)=0.55 \mathrm{~m}$; soil permeability $(K)=1.5 \times 10^{-5} \mathrm{~m} / \mathrm{s}$; soil porosity $\left(n_{s}\right)=0.51$; shear modulus $(G)=1.92 \times 10^{6} \mathrm{~N} / \mathrm{m}^{2}$; seabed thickness $(h)=0.4 \mathrm{~m}$; Poisson's ratio $\left(\mu_{s}\right)=0.29$; Consolidation coefficient $\left(c_{v}\right)=0.0127 \mathrm{~m}^{2} / \mathrm{sec}$; Relative density of soil $\left(D_{r}\right)=0.28$; coefficient of lateral earth pressure $\left(K_{o}\right)=0.42$; degree of saturation $S_{r}=1.0$; and submerged specific weight of soil $\left(\gamma^{\prime}\right)=8.14 \mathrm{KN} / \mathrm{m}^{3}$. Fig. 4 shows the comparison of the present model and the experimental data for the depth variation of the residual pore pressure. As shown in Fig.4, the numerical results from the present model overall agree with the experimental data [40], especially in the first two wave cycles. The discrepancy may be attributed to the theory of poro-elasticity used in the present study. Therefore, the present model can only provide a first-hand approximation for the build-up of residual pore pressure up 
to the occurrence of liquefaction. A more sophisticated elasto-plastic model [47] incorporating with post-liquefaction processes is required in the future work.

\section{Results and discussions}

\subsection{Wave-seabed-breakwater interactions}

It has been well known that the wave-induced oscillatory shear stress will affect the waveinduced residual pore pressure, thus affecting the wave-induced residual liquefaction. Unlike the previous studies, the phase-resolved oscillatory shear stress is used as the source of pore pressure accumulation in the present study. Two mainly reasons attributed to this assumption which can be concluded as: (1) the source term was determined by the oscillatory shear stress which should be a time-dependent function; (2) considering the complicated interaction between the wave, breakwater and seabed foundation, phase-resolved shear stress is a better choice, which can link oscillatory and residual mechanisms instantaneously, compared with the shear stress amplitude over wave period used in the previous studies $[8,9]$.

Fig. 7 illustrates the wave-induced oscillatory pore pressure $\tilde{p}$ and shear stress $\tilde{\tau}$ at different times. When the wave propagates over the breakwater, the water depth gradually decreases with respect to the initial depth due to the presence of the sloping seabed. The wave does not break on the slope until it reaches the breakwater. There is a complicated interaction between the wave and breakwater resulting in a significant amount of turbulence generated in the vicinity of breakwater at $t=54 \mathrm{~s}$. A large flow circulation is formed around the left top corner of structure, where the horizontal component of velocity is very small compared to the vertical component. The distribution of wave-induced oscillatory pore pressure is directly related to the free surface of ocean waves. The soil is subject to compression under wave crest while it is subject to decompression under wave trough. There exists a phase lag between the wave-induced shear stress in the seabed and the wave propagating on the seabed. The wave height in front of the breakwater becomes nearly double of the original wave height due to reflection at $t=60 \mathrm{~s}$, resulting in an increase in the magnitude of both pore pressure and shear stress. Another part of the wave will overtop the breakwater leading to the free surface of the sea water behind the breakwater to vibrate freely. At this time, the wave decays obviously as part of incident wave energy has been dissipated due to the wave-structure interaction. As a result, smaller magnitude 
of both pore pressure and shear stress is observed in this region compared to that in front of the breakwater. It is interesting to see that there always exists a shear stress concentration zone at the toe of the breakwater, which becomes more significant when the wave height increases in front of the breakwater. This phenomenon can be attributed to significant different stiffness at the interface between the breakwater and seabed foundation.

Under the action of cyclic progressive wave loading, the residual pore pressure builds up with the increasing wave cycle $t / T$. At the same time, in the region close to the upper seabed, the pore pressure gradually decreases due to dissipation. The resulting accumulated residual pore pressure become very significant at two locations, one is in front of the breakwater where the soil is subject to large wave loadings due to reflection, the other is located at the left toe of the breakwater where there always exists a shear stress concentration zone.

Fig. 9 illustrates the wave-induced pore pressure build-up at four different locations with the same vertical distances from the bed surface: A $(x=215 \mathrm{~m}, z=3.8 \mathrm{~m}), \mathrm{B}(x=235 \mathrm{~m}, z=4.2 \mathrm{~m}), \mathrm{C}$ $(x=250 \mathrm{~m}, z=4.5 \mathrm{~m}), \mathrm{D}(x=300 \mathrm{~m}, z=5.5 \mathrm{~m})$. As shown in the figure, it takes approximately four wave cycles for the wave to reach the breakwater. After the interaction between the wave and the structure is developed, the pore pressure begins to build up. A relatively slow increase in the magnitude of pore pressure accumulation is observed when the first one or two waves passing through the breakwater. This is due to that the wave is not matured enough in the early stages resulting in a relatively small wave height. It is much easier for the pore pressure to build up in location $\mathrm{B}$ and $\mathrm{C}$ where the shear strains are most significant (referring to Fig. 7) compared to that in location $\mathrm{A}$ and $\mathrm{D}$. The pore pressure $\left(p_{s}, \bar{p}_{s}\right)$ buildup very quickly and accumulate to a large value in the location at the toe of the breakwater $(\mathrm{C})$. Two mainly reasons can attribute to this phenomenon. One is because the impermeable interface between the breakwater and seabed surface significantly affect the dissipation rate of residual pore pressure. The other is due to a shear strain concentration induced by a significant different stiffness between the breakwater and seabed surface.

\subsection{Wave-induced residual liquefaction}

It has been commonly recognized that the seabed would liquefy and behaves like a kind of heavy liquid when the residual pore pressure $\bar{p}_{s}$ is greater than the initial effective stress [7], which can be shown as: 


$$
-\frac{1+2 K_{0}}{3}\left(\gamma_{s}-\gamma_{w}\right) z+\bar{p}_{s} \leq 0
$$

where $\gamma_{s}$ is the saturation unit weight of seabed soil, $\gamma_{w}$ is the unit weight of sea water, $K_{0}$ is the coefficient of lateral earth pressure, $P_{b}$ is the pore pressure on the mudline, $p$ is the field of pore pressure in seabed. Actually, the first item: $\frac{1+2 K_{0}}{3}\left(\gamma_{s}-\gamma_{w}\right) z$ means the initial normal effective stress. It has been reported in previous studies that the coastal structure significantly affects the stress fields in the seabed foundation, compared to that without any structure [20, 27]. After the breakwater is constructed on seabed, the seabed foundation will reach a new equilibrium consolidation status induced by the self-weight of the breakwater. Therefore, for the cases in which there are marine structures constructed on the seabed, Eq. (20) should be modified as

$$
-\frac{1+\mu_{s}}{3}\left(\sigma_{s z}^{\prime}+\sigma_{s x}^{\prime}\right)+\bar{p}_{s} \leq 0
$$

In this study, the actual initial effective stresses can be obtained from the present numerical model under static loadings including the static water pressures and the weight of the breakwater. Then, this consolidation status is taken as the initial condition in the analysis of the wave-seabed-structure interaction problem. It can be seen in Fig. 5, in the region close to the breakwater, the effective stresses increase toward the bottom and there is a stress concentration beneath the breakwater, which can be attributed to the significant different stiffness at the interface between the breakwater and seabed foundation. The distribution is layered in the region far away from the breakwater, which comes from the self-gravity of seabed soil. This indicates that the effects of breakwater on the stress field basically disappear. The minimum effective stress occurs in the region near the seabed surface. In this region, the excess pore pressure can easily exceed the reduced effective overburden pressure, which will cause the sand to liquefy. It is also found that the seabed foundation under the breakwater moves toward its left and right sides, and subsides downward under static loadings. Due to the fact that the breakwater is built on a sloping seabed, the magnitude of the displacement toward left side is greater than that toward right side. The magnitudes of horizontal and vertical displacement are approximately 35 $\mathrm{mm}$ and $700 \mathrm{~mm}$ respectively. 
The comparison for the development of liquefaction zone between two different approaches: (a) without pre-consolidation due to self-weight of a breakwater, i.e., (20); and (b) with preconsolidation due to self-weight of a breakwater, i.e., (21), is illustrated in Fig. 6. As shown in the figure, the soil is more likely to be liquefied for the case where the effect of self-weight of breakwater on the initial consolidation status is neglected, especially in the location at the breakwater toes. Consequently, the previous determination for the initial consolidation state will significantly overestimate the liquefaction depth.

\subsection{Effect of wave characteristics}

In general, wave characteristics play an important role in the evaluation of the seabed response in a porous seabed [6]. Since the wave-induced oscillatory mechanism has a significant influence on the residual mechanism of seabed response. Both the wave-induced oscillatory and residual mechanisms will be discussed in this section. Four representative locations in the vicinity of breakwater: A $(x=215 \mathrm{~m}), \mathrm{B}(x=235 \mathrm{~m}), \mathrm{C}(x=250 \mathrm{~m}), \mathrm{D}(x=300 \mathrm{~m})$ are selected in this analysis. Regarding the analysis for the wave-induced oscillatory pore pressure, the seabed characteristics are selected as: soil permeability $(K)=10^{-2} \mathrm{~m} / \mathrm{s}$; soil porosity $\left(n_{s}\right)=0.3$; shear modulus $(G)=10^{7} \mathrm{~N} / \mathrm{m}^{2}$; Poisson's ratio $\left(\mu_{s}\right)=0.35$; and the degree of saturation $\left(S_{r}\right)=0.975$. Regarding the analysis for the wave-induced residual pore pressure, the seabed characteristics are selected as: relative density of seabed $\left(D_{r}\right)=0.3$, soil permeability $(K)=10^{-5} \mathrm{~m} / \mathrm{s}$; soil porosity $\left(n_{s}\right)=0.4$; shear modulus $(G)=10^{7} \mathrm{~N} / \mathrm{m}^{2}$; Poisson's ratio $\left(\mu_{s}\right)=0.35$; and the degree of saturation $\left(S_{r}\right)=1$. Various wave heights $(H)$ and wave periods $(T)$ are studied here with a fixed still water depth $(d=16 \mathrm{~m})$.

\subsubsection{Effect of wave height}

Wave height can directly affect the wave forces, pressures and energy acting on the structures, and then affecting the wave-induced pore pressure and effective stresses in marine sediments [32]. Fig. 10 illustrates the vertical distribution of the maximum oscillatory pore pressure $\left(|p| / \gamma_{w} d\right)$ at four different locations with three different wave heights $(H=3,4$ and $5 \mathrm{~m})$. It is noted that the wave height will vary during the highly non-linear interaction process between wave, slope seabed and breakwater. Thus the wave heights mentioned here are the original 
incident wave heights with period $T=10 \mathrm{~s}$. As shown in the figure, the maximum value of oscillatory pore pressure occurs in location $\mathrm{A}(x=215 \mathrm{~m})$ where the wave height increases due to reflection in front of a breakwater. Due to the energy dissipation induced by the wave-seabedbreakwater interaction, the oscillatory pore pressure behind the breakwater is much smaller compared to that in front of a breakwater. The pore pressure increases with increasing wave heights as a higher wave height induces a higher magnitude of wave pressure on the seabed.

Fig. 11 illustrates the effect of wave height $(H)$ on the vertical distribution of accumulation of residual pore pressure at four different locations. The residual pore pressure are greater in front of the breakwater (locations A and B) and at the left toe of the breakwater (location C) compared to that behind the breakwater (location D). Different from the wave-induced oscillatory pore pressure, the maximum magnitude of accumulated residual pore pressure occurs in location $\mathrm{C}(x=250 \mathrm{~m})$ where the shear strains are more significant as well as a more difficult dissipation condition induced by the impermeable interface between the breakwater and seabed surface. The residual pore pressure $\left(\bar{p}_{s}\right)$ is more likely to accumulate to a large value in the location at the left toe of the breakwater $(x=250 \mathrm{~m})$. Two mainly reasons can attribute to this phenomenon. One is because the impermeable interface between the breakwater and seabed surface significantly affect the dissipation rate of residual pore pressure. The other is due to a shear strain concentration induced by a significant different stiffness between the breakwater and seabed surface. However, due to the effect of self-weight of the breakwater, the initial effective stress $\left(\sigma_{0}^{\prime}\right)$ at the surface of seabed at the left toe of the breakwater is much larger than that in the region far away from the breakwater. As a result, it is more difficult for the residual pore pressure in this location (location C) to overcome the overburdened weight of the soil compared to that in front of the breakwater (location B), especially for the soil close to the seabed surface (see Fig. 12). Similar to the wave-induced oscillatory pore pressure, the residual pore pressure can accumulate to a large value for the case of large wave height. The accumulated pore pressure behind the breakwater (location D) is much smaller compared to that in the other locations (locations A, B and C).

The development of liquefaction potential for the cases with various wave heights $(H)$ are illustrated in Fig. 12. It is found that there are two liquefied zones developing first in front of and at the left toe of the breakwater for the case with $H=5 \mathrm{~m}$, respectively, where the 
shear strains are most significant. They are extended laterally and vertically to neighbouring points and eventually are connected together. The liquefaction potential in the case of $H=5 \mathrm{~m}$ developed faster compared to the other cases with $H=3 \mathrm{~m}$ and $H=4 \mathrm{~m}$, indicating that the soil is more likely to be liquefied under large wave loading.

\subsubsection{Effect of wave period}

Wave period is another wave variable directly affecting the wavelength, i.e., wave number, which has been involved in most wave characteristics. In this example, three different wave periods, $T=9,10$ and 11 seconds with fixed wave height $H=5 \mathrm{~m}$ are considered. In general, a shorted wave (smaller wave period) will reduced the wavelength, and leads to larger relative depth $(d / L)$ with fixed water depth. This is the reason why a longer wave period will cause large magnitude of oscillatory pore pressure in the seabed, as shown in Fig. 13.

As mentioned previously, longer wave period can result in longer wave length. The residual pore pressure should accumulate to a large value as the shear strains owing to the wave length increases. However, a contradictory result is observed in Fig. 14 where the residual pore pressure can accumulate to a large value for the case with a short wave period. This is because the pore pressure accumulation is not only related to the shear stress ratio $\left(\tau / \sigma_{0}^{\prime}\right)$ but also related to the period of cyclic loadings. The pore pressure and energy are more difficult to drain out in a short duration. It is interesting to be observed from Fig. 15 that, there is a significant difference for the development of liquefaction zone along $x$ - direction compared to that along $z$ - direction. This may be induced by the difference in wave length in relation to various wave periods.

\subsection{Effect of seabed characteristics}

Besides the wave characteristics, soil properties are also important for wave-induced pore pressure accumulation in marine sediments. To investigate the influence of soil characteristics on the wave-induced seabed response, a wave with period $T=10 \mathrm{~s}$, height $H=5 \mathrm{~m}$ and water depth $d=16 \mathrm{~m}$, which lead to the relative water depth as $d / L=0.1$, are used in the following examples. The soil characteristics examined here for the wave-induced seabed response include the soil permeability $(K)$ and relative density $\left(D_{r}\right)$ of the soil. 


\subsubsection{Effect of permeability of the soil}

Both the wave-induced oscillatory and residual pore pressure are significantly affected by the permeability of the soil. As shown in Fig. 16, compared to the case with $K=10^{-2} \mathrm{~m} / \mathrm{s}$, the pore pressure attenuates very rapidly within the top $10 \%$ of its thickness for the case with $K=10^{-4} \mathrm{~m} / \mathrm{s}$. This could be attributed to the region where oscillatory liquefaction may occur. It can be observed from Fig. 17 that, the pore pressure builds up faster and accumulates to a larger value with low soil permeability. As the energy and pore pressure are more difficult to drain out in the soil with a low permeability. The magnitude of both oscillatory pore pressure and residual pore pressure in the location in front of the breakwater are greater than that behind the breakwater. This phenomenon can be attributed to the increment of wave energy in front of the breakwater due to wave reflection and wave energy dissipation behind the breakwater induced by the wave-breakwater interaction.

The development of liquefaction zone is significantly affected by the soil permeability $(K)$, especially in the location at the left toe of the breakwater. This may be attributed to the impermeable interface between the breakwater and seabed foundation. The soil at the left toe of the breakwater is more likely to be liquefied as the permeability decreases, as shown in Fig. 18.

\subsubsection{Effect of relative density}

According to (6), the build-up empirical coefficients $\alpha_{r}$ and $\beta_{r}$ which are related to the relative density $\left(D_{r}\right)$ significantly affect the accumulation of residual pore pressure. Since there is no relationship between the wave-induced oscillatory soil response and relative density $\left(D_{r}\right)$, only the effect of relative density $\left(D_{r}\right)$ on the wave-induced residual soil mechanism is examined in this section. Figs. 19 and 20 illustrate the distributions of pore pressure accumulation versus wave cycle and the mechanism of development of liquefaction zone for various relative density $\left(D_{r}\right)$ of the soil. It is found that the pore pressure builds up faster and accumulates to a larger value in the soil with low relative density. A decrease value of relative density $\left(D_{r}\right)$ from 0.4 to 0.3 can increase the value of pore pressure accumulation at the left toe of breakwater $((x, z)=(250,4.5) \mathrm{m})$ to more than half. This implies that the residual liquefaction is more likely to occur in a soil with low relative density. Associated with the progress of pore pressure accumulation, the liquefaction zone in front of the breakwater and at the left toe of the breakwater developed faster in the case of the soil with low relative density. 


\subsection{Effect of slope gradients}

It is well known that the water depth $(d)$ for a progressive wave propagating over a sloping seabed will gradually decrease. The decrease in water depth $(d)$ results in the decrease in the wavelength $(L)$ with a fixed wave period $(T)$. When the wave height $(H)$ is same, decrease of the wavelength will lead to large wave steepness $(H / L)$ and hence more close to breaking waves. Due to the fact that the rate of decrease in water depth $(d)$ increases with increasing bed slope $(\theta)$. The wave propagates on a steep slope should result in a more remarkable hydrodynamic force $\left(P_{w}\right)$ acting on the seabed foundation, as shown in Fig. 21. Note that the wave breaking shown in Fig. 21 in the case of $\theta=1: 30$ may be not solely caused by shoaling, but also related to the interferences between incident and reflected waves induced by the block effect of breakwater. Corresponding to the effect of wave forces, the vertical distribution of waveinduced maximum oscillatory pore pressure $\left(|p| / \gamma_{w} d\right)$ in the vicinity of the breakwater increases as the bed slope $(\theta)$ increases, as shown in Fig. 22. The difference in $|p| / \gamma_{w} d$ induced by the bed slope $(\theta)$ become more significant in the location with a larger $x$ - coordinate. Similar trends can be observed in Fig. (23) with respect to the vertical residual pore pressure $\left(\bar{p}_{s} / \gamma_{w} d\right)$. The effect of slope gradients $(\theta)$ on the development of liquefaction zone is illustrated in Fig. 24. It is found that the soil resting on a steep slope is more likely to be liquefied. For a flat seabed $(\theta=0)$, no liquefaction occurs at the left toe of the breakwater.

\subsection{Effect of trench layer}

As discussed previously, there exists a liquefaction potential at the left toe of the breakwater. This may result in the collapse or tilting of breakwaters. It has been recognized that the residual liquefaction is more difficult to happen in the soil with a high permeability. Therefore, the trenches backfilled by selected coarse-grained sand are recommended to use at the left toe of the breakwater to enhance the protection of the seabed foundation from the soil instability. It can be observed from Fig. 25 that the development of liquefaction is strongly impacted by the existence of trench layer, the seabed foundation below the left toe of the breakwater without a trench layer and nearby zone in front of the breakwater is liquefied after a certain wave period. While for the case with a trench layer, no liquefaction occurs at the left toe of the breakwater, indicating that the trench layer backfilled by coarse sand will effectively protect the seabed foundation from the wave-induced liquefaction with the selected wave and seabed characteristics in Table 1. 


\subsection{Effect of permeability of breakwater}

All of the case studies mentioned above considered that the breakwater is impermeable $\left(K_{b}=0\right)$. In the case of a permeable breakwater such as a rubble mound breakwater, the cyclic loads are directly transferred by the wave motion into the rubble mound breakwater and the subsoil, as shown in Fig. 26. It can be also observed from Fig. 26 that the residual pore pressure is more likely to accumulate to a large value below the breakwater, which may be attributed to the large difference of the flow in the pore between breakwater and seabed. Corresponding to this, the effect of permeability of breakwater $\left(K_{b}\right)$ on the vertical distribution of accumulated residual pore pressure and resulting liquefaction potential in the vicinity of breakwater is remarkable, especially in the region below the breakwater, as shown in Figs. 27 and 28. Therefore, more detailed analysis in regard to the interactions between wave, seabed foundation and permeable breakwater is required in the future study.

\section{Conclusions}

In this study, we developed a 2-D integrated model to investigate the wave-induced seabed response in the vicinity of breakwater over sloping seabed, in which both the oscillatory mechanisms and residual mechanisms are considered. Based on the numerical results, the following conclusions can be drawn:

(1) Numerical comparisons illustrated an overall agreement between the present model and previous experimental results for both oscillatory and residual pore presses.

(2) The initial consolidation state of seabed foundation is significantly affected by the selfweight of the breakwater. This consolidation state can effectively protect the seabed foundation from the wave-induced liquefaction.

(3) There is intensive interaction between wave, breakwater and slope seabed foundation. The combination of incident wave and reflected wave results in a double wave height with respect to the original wave height in front of the breakwater. The wave decays obviously after it overtop the breakwater. Corresponding to this, the wave-induced oscillatory mechanisms including the wave induced dynamic shear stress and oscillatory pore pressures as well as the wave-induced build-up of residual pore pressure in the location in front of the breakwater are normally greater than that behind the breakwater. 
(4) The soil is more likely to be liquefied in the case of low permeability $(K)$ and low relative density $\left(D_{r}\right)$ under the conditions of larger amplitude waves with smaller wave period. The effect of bed slope on the build-up of residual pore pressure is significant. The potential for liquefaction increases as the bed slope increases.

(5) The permeability of breakwater significantly affect the wave-induced seabed response in the vicinity of the breakwater. In the case of an impermeable breakwater, the liquefaction zone normally occurs initially in front of the breakwater and at the toe of the breakwater where the shear strains are most significant. Then the liquefied zones are extended laterally and vertically to the neighbouring points and eventually are connected together under certain conditions. For the region below the breakwater, no obvious potential for liquefaction is observed. This is contradictory to that in the case of a permeable breakwater.

\section{Acknowledgements}

The authors gratefully acknowledge the support of the Griffith University eResearch Service team and the use of the High Performance Computing Cluster Gowonda to complete this research. The first author thanks for the support of Griffith University Deputy Vice Chancellor (Research) International Postgraduate Scholarship and SEET Postgraduate Research Scholarship.

\section{References}

[1] R. Silvester, J. R. C. Hsu, Sines revisited, Journal of Waterway, Port, Coastal, Ocean Engineering, ASCE 115 (3) (1989) 327-344.

[2] K. Zen, H. Yamazaki, Mechanism of wave-induced liquefaction and densification in seabed, Soils and Foundations 30 (4) (1990) 90-104.

[3] H. Nago, S. Maeno, T. Matsumoto, Y. Hachiman, Liquefaction and densification of loosely deposited sand bed under water pressure variation, in: Proceeding of the 3rd international offshore and Polar Engineering Conference, Singapore, Vol. I, 1993, pp. 578-584. 
[4] O. S. Madsen, Wave-induced pore pressures and effective stresses in a porous bed, Géotechnique 28 (4) (1978) 377-393.

[5] T. Yamamoto, H. Koning, H. Sellmeijer, E. V. Hijum, On the response of a poro-elastic bed to water waves, Journal of Fluid Mechanics 87 (1) (1978) 193-206.

[6] J. R. C. Hsu, D.-S. Jeng, Wave-induced soil response in an unsaturated anisotropic seabed of finite thickness, International Journal for Numerical and Analytical Methods in Geomechanics 18 (11) (1994) 785-807.

[7] H. B. Seed, M. S. Rahman, Wave-induced pore pressure in relation to ocean floor stability of cohesionless soils, Marine Geotechnology 3 (2) (1978) 123-150.

[8] B. M. Sumer, J. Fredsøe, The Mechanism of Scour in the Marine Environment, World Scientific, New Jersey, 2002.

[9] D.-S. Jeng, B. R. Seymour, A simplified analytical approximation for pore-water pressure build-up in a porous seabed, Journal of Waterway, Port, Coastal, and Ocean Engineering, ASCE 133 (4) (2007) 309-312.

[10] M. A. Biot, General theory of three-dimensional consolidation, Journal of Applied Physics 26 (2) (1941) 155-164.

[11] C. C. Mei, M. A. Foda, Wave-induced response in a fluid-filled poro-elastic solid with a free surface-a boundary layer theory, Geophysical Journal of the Royal Astronomical Society 66 (1981) 597-631.

[12] D.-S. Jeng, J. R. C. Hsu, Wave-induced soil response in a nearly saturated seabed of finite thickness, Géotechnique 46 (3) (1996) 427-440.

[13] C. P. Tsai, Wave-induced liquefaction potential in a porous seabed in front of a breakwater, Ocean Engineering 22 (1) (1995) 1-18.

[14] D.-S. Jeng, Wave-induced liquefaction potential at the tip of a breakwater, Applied Ocean Research 18 (5) (1996) 229-241. 
[15] D.-S. Jeng, Wave-induced seabed instability in front of a breakwater, Ocean Engineering 24 (10) (1997) 887-917.

[16] H. Mase, T. Sakai, M. Sakamoto, Wave-induced porewater pressure and effective stresses around breakwater, Ocean Engineering 21 (4) (1994) 361-379.

[17] D.-S. Jeng, D. H. Cha, Y. S. Lin, P. S. Hu, Wave-induced pore pressure around a composite breakwater, Ocean Engineering 28 (10) (2001) 1413-1432.

[18] N. Mizutani, A. M. Mostafa, Nonlinear wave-induced seabed instability around coastal structures, Coastal Engineering Journal 40 (2) (1998) 131-160.

[19] A. M. Mostafa, N. Mizutani, K. Iwata, Nonlinear wave, composite breakwater and seabed dynamic interaction, Journal of Waterway, Port, Coastal, and Ocean Engineering, ASCE 125 (2) (1999) 88-97.

[20] M. Ulker, M. S. Rahman, M. N. Guddati, Wave-induced dynamic response and instability of seabed around caisson breakwater, Ocean Engineering 37 (2010) 1522-1545.

[21] C. J. Huang, H. H. Chang, H. H. Hwung, Structural permeability effects on the interaction of a solitary wave and a submerged breakwater, Coastal Engineering 49 (2003) 1-24.

[22] D. S. Hur, C. H. Kim, D. S. Kim, J. S. Yoon, Simulation of the nonlinear dynamic interactions between waves, a submerged breakwater and the seabed, Ocean Engineering (2008) $511-522$.

[23] D. S. Hur, C. H. Kim, J. S. Yoon, Numerical study on the interaction among a nonlinear wave, composite breakwater and sandy seabed, Coastal Engineering 57 (10) (2010) 917 930.

[24] J. L. Lara, N. Garcia, I. J. Losada, Rans modeling applied to random wave interaction with submerged permeable structures, Coastal Engineering 53 (2006) 395-417.

[25] P. L.-F. Liu, P. Lin, K. A. Chang, T. Sakakiyama, Numerical modelling of wave interaction with porous structures, Journal of Waterway, Port, Coastal and Ocean Engineering, ASCE 125 (6) (1999) 322-330. 
[26] S. H. Shao, Incompressible sph flow model for wave interactions with porous media, Coastal Engineering 57 (2010) 304-316.

[27] D.-S. Jeng, J. H. Ye, J. S. Zhang, P.-F. Liu, An integrated model for the wave-induced seabed response around marine structures: Model verifications and applications, Coastal Engineeirng Journal 72 (2013) 1-19.

[28] P. Lin, P. L.-F. Liu, A numerical study of breaking waves in the surf zone, Journal of Fluid Mechanics 359 (1998) 239-264.

[29] S. Y. Tzang, Unfluidized soil responses of a silty seabed to monochromatic waves, Coastal Engineering 35 (4) (1998) 283-301.

[30] B. M. Sumer, J. Fredsøe, S. Christensen, M. L. Lind, Sinking/floatation of pipelines and other objects in liquefied soil under waves, Coastal Engineering 38 (1999) 53-90.

[31] L. Cheng, B. M. Sumer, J. Fredsöe, Solution of pore pressure build up due to progressive waves, International Journal for Numerical and Analytical Methods in Geomechanics 25 (2001) 885-907.

[32] D.-S. Jeng, Porous Models for Wave-seabed Interactions, Springer, 2013.

[33] Sumer, Liquefaction around marine structures, World Scientific, New Jersey, USA, 2014.

[34] S. Sassa, H. Sekiguchi, Analysis of wave-induced liquefaction of sand beds, Géotechnique 51 (2) (2001) 115-126.

[35] S. Sassa, H. Sekiguchi, Wave-induced liquefaction of beds of sand in a centrifuge, Géotechnique 49 (5) (1999) 621-638.

[36] J. Li, D.-S. Jeng, Response of a porous seabed around breakwater heads, Ocean Engineering35 (8-9) (2008) 864-886.

[37] D.-S. Jeng, J. Ou, 3-d models for wave-induced pore pressure near breakwater heads, Acta Mechanica 215 (1-4) (2010) 85-104. 
[38] J. H. Ye, D.-S. Jeng, R. Wang, C. Zhu, Numerical study of the stability of breakwater built on a sloped porous seabed under tsunami loading, Applied Mathematical Modelling 37 (2013) 9575-9590.

[39] J. H. Ye, D.-S. Jeng, P.-F. Liu, A. Chan, R. Wang, C. Zhu, Breaking wave-induced response of composite breakwater and liquefaction in seabed foundation, Coastal Engineeirng Journal 85 (2014) 72-86.

[40] B. M. Sumer, V. S. O. Kirca, J. Fredsøe, Experimental validation of a mathematical model for seabed liquefaction under waves, International Journal of Offshore and Polar Engineering 22 (2012) 133-141.

[41] Rodi, Turbulence Models and their Application in Hydraulics-State-of-The-Art Review, 3rd edn., Balkema, 1993.

[42] P. Lin, P. L.-F. Liu, Internal wave-maker for navier-stokes equations models, Journal of Waterway, Port, Coastal, and Ocean Engineering, ASCE 125 (4) (1999) 207-215.

[43] J. Ye, D.-S. Jeng, Response of seabed to natural loading-waves and currents, Journal of Engineering Mechanics, ASCE 138 (6) (2012) 601-613.

[44] L. G. Bierawski, S. Maeno, Vof-fem numerical model of submerged breakwater on permeable bottom, Journal of Applied Mechanics JSCE 7 (2004) 945-952.

[45] COMSOL, COMSOL Multiphysics. 3rd ed.; 2010., COMSOL, Inc., 2010.

[46] B. Liu, D.-S. Jeng, Laboratory study for pore pressure in sandy bed under wave loading, in: The 23rd (2013) International Offshore and Polar Engineering Conference (ISOPE2013), Anchorage, Alaska, USA 2013, 2013, pp. 1432-1437.

[47] S. Sassa, H. Sekiguchi, J. Miyamamot, Analysis of progressive liquefaction as movingboundary problem, Géotechnique 51 (10) (2001) 847-857. 
Table 1: Input data in the numerical examples.

\begin{tabular}{ll}
\hline Wave characteristics & \\
\hline Wave period $(T)$ & $10(\mathrm{~s})$ or various \\
Wave height $(H)$ & $5(\mathrm{~m})$ or various \\
Water depth $(d)$ & $16(\mathrm{~m})$ \\
\hline Seabed characteristics & \\
\hline Soil porosity $\left(n_{e}\right)$ & 0.3 \\
Poisson's ratio $(\mu)$ & 0.35 \\
Shear modulus $(G)$ & $10^{7}(\mathrm{~N} / \mathrm{m})^{2}$ or various \\
Soil permeability $(K)$ & $10^{-5}(\mathrm{~m} / \mathrm{s})$ or various \\
Degree of saturation $\left(S_{r}\right)$ & 1 or various \\
Relative density $\left(D_{r}\right)$ & 0.3 or various \\
\hline Trench layer & \\
\hline Soil porosity $\left(n_{e}\right)$ & 0.3 \\
Poisson's ratio $(\mu)$ & 0.35 \\
Shear modulus $(G)$ & $10^{7}(\mathrm{~N} / \mathrm{m})^{2}$ \\
Soil permeability $(K)$ & $10^{-3}(\mathrm{~m} / \mathrm{s})$ \\
Degree of saturation $\left(S_{r}\right)$ & 1 \\
Relative density $\left(D_{r}\right)$ & 0.3 \\
\hline
\end{tabular}




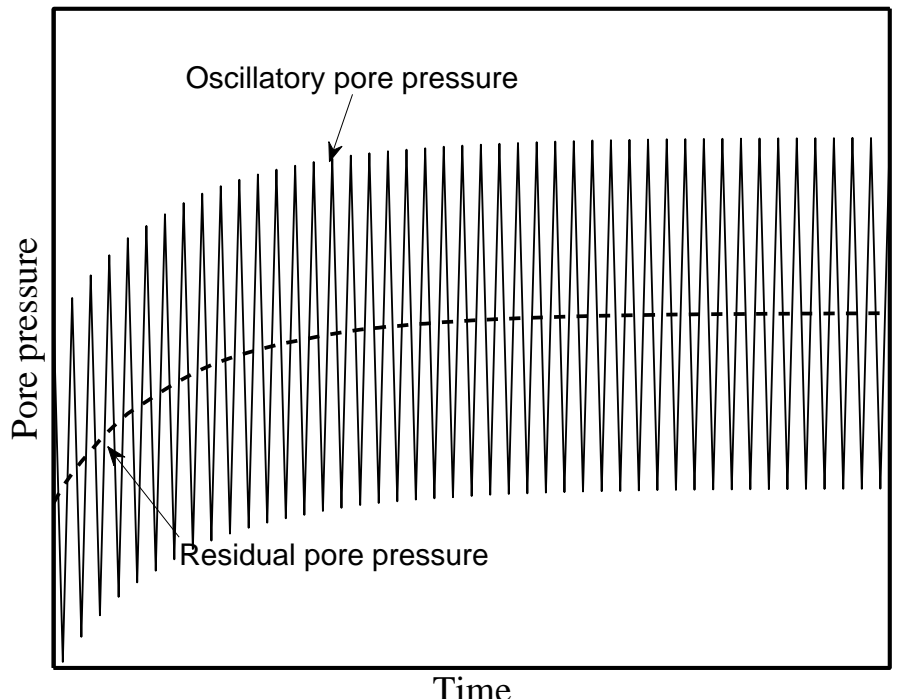

Figure 1: Mechanisms of wave-induced pore pressures. 


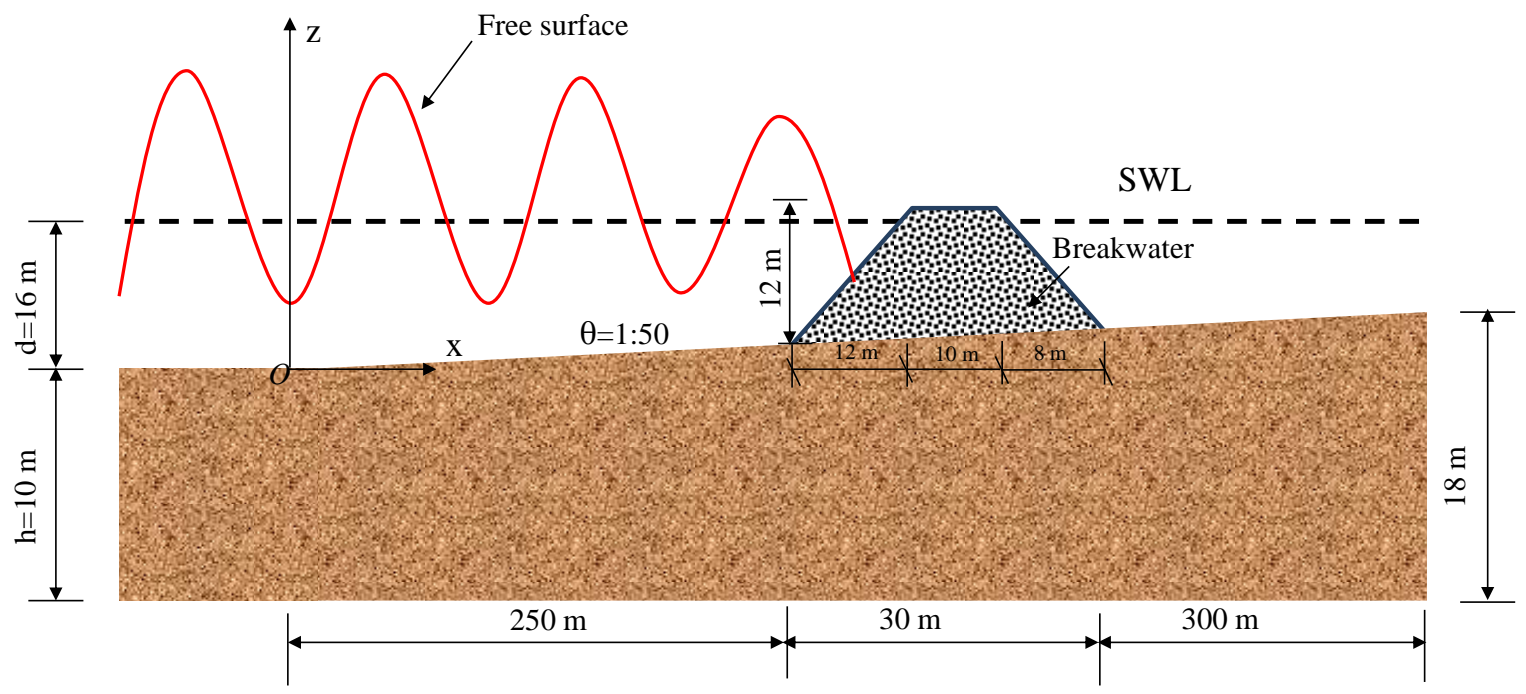

Figure 2: The sketch map of the computational domain adopted in this study. 


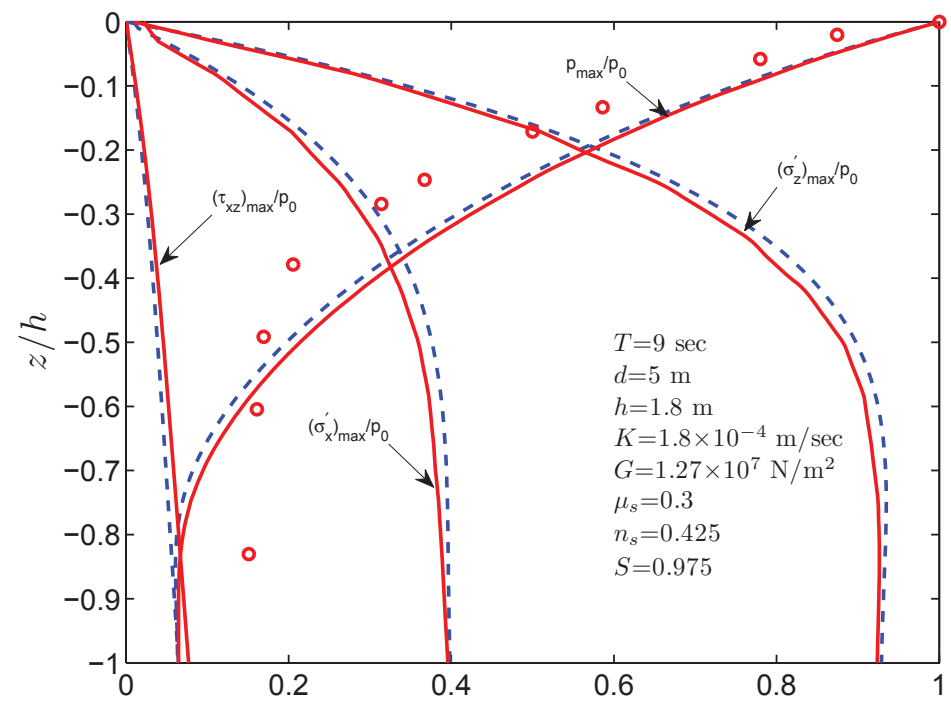

Figure 3: The comparison of vertical distribution of maximum wave-induced oscillatory pore pressure versus relative soil depth with the 1-D experimental results (symbols, [46]) and the analytical solution (dashed lines, [6]. 


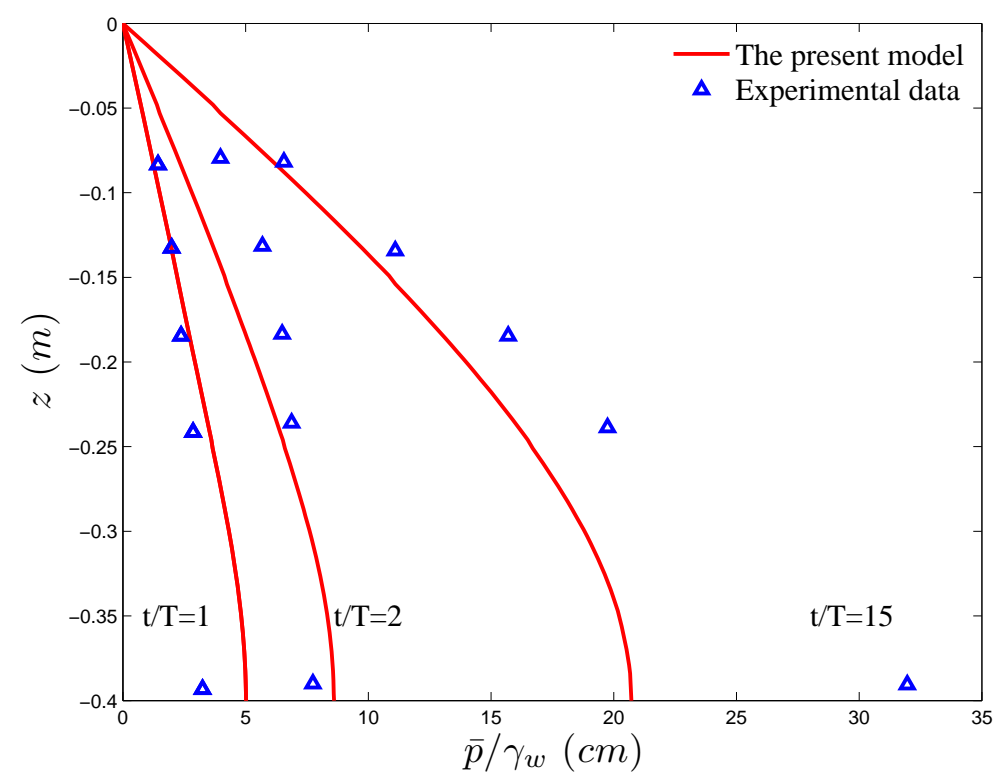

Figure 4: Comparison of model results and experimental data [40]. 

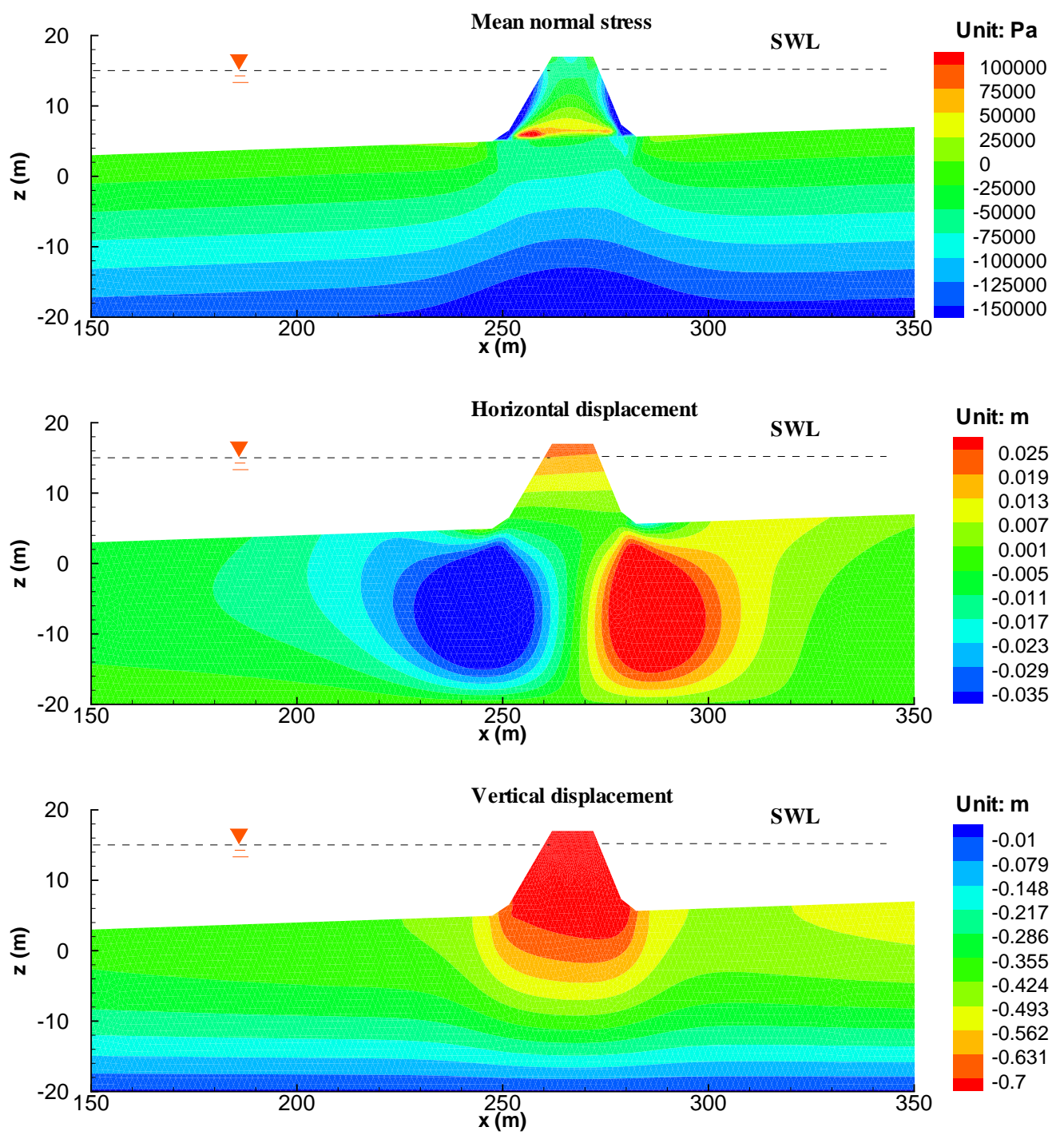

Figure 5: The distribution of the effective stress and displacements after consolidation in sloping seabed. 
(a)

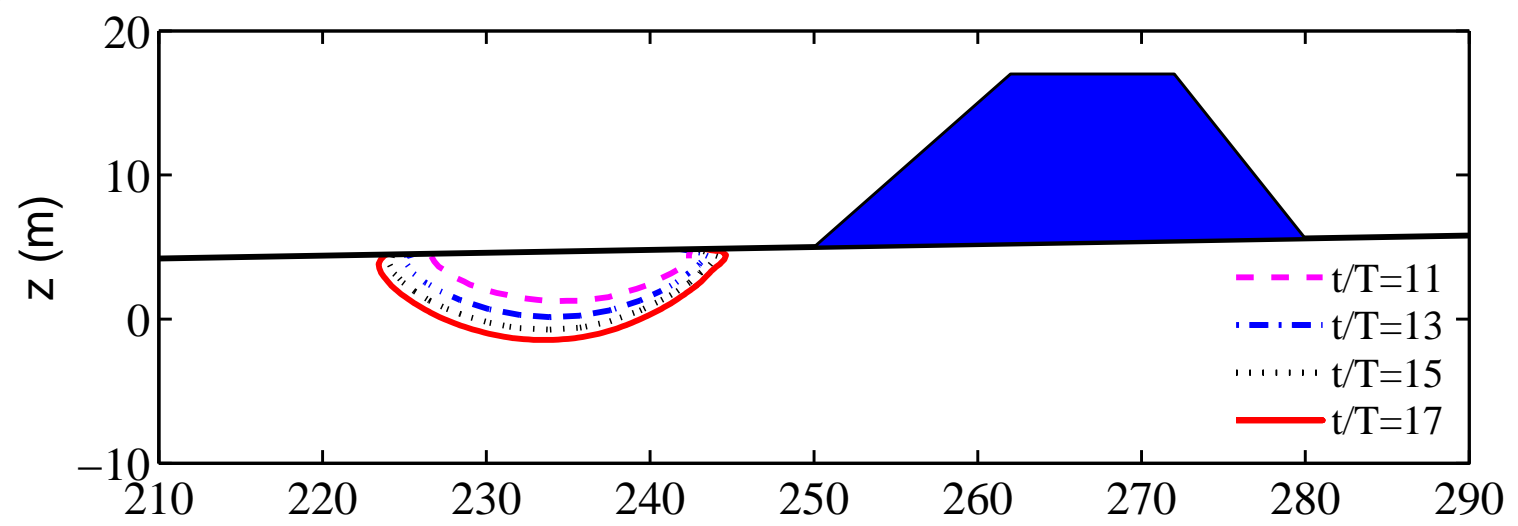

(b)

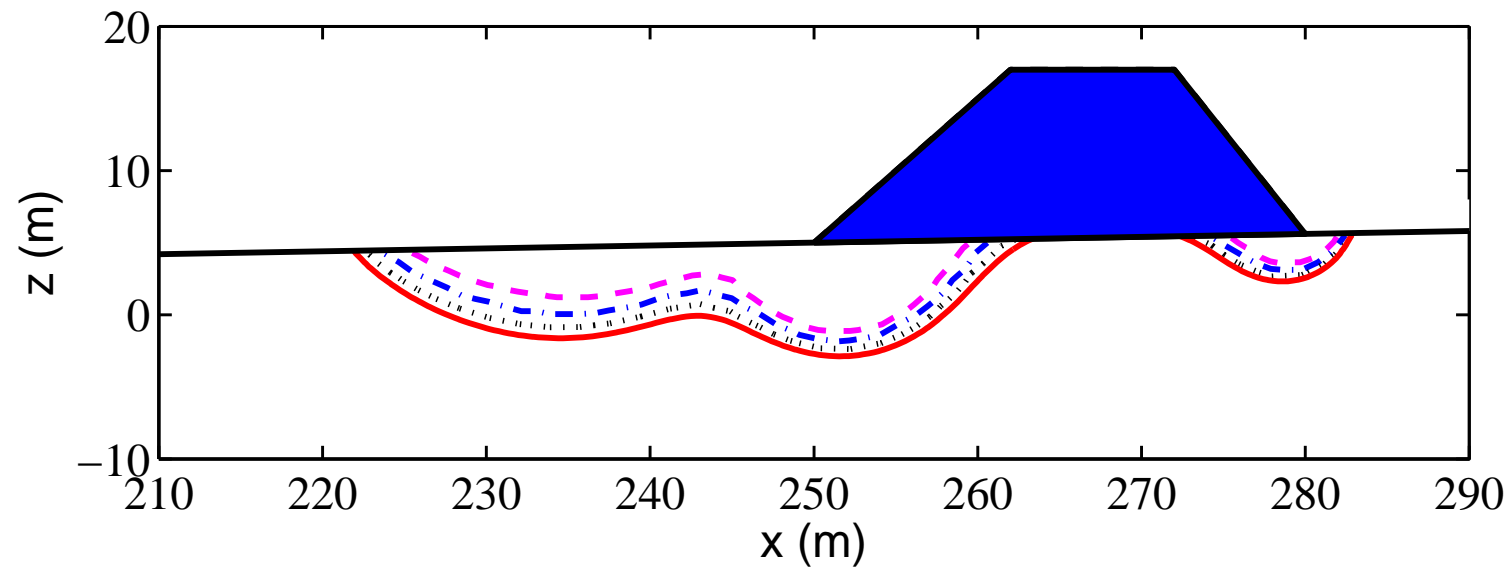

Figure 6: Development of liquefaction zone in the vicinity of the breakwater (a) without pre-consolidation due to the self-weight of a breakwater.; and (b) with pre-consolidation due to self-weight of a breakwater. 

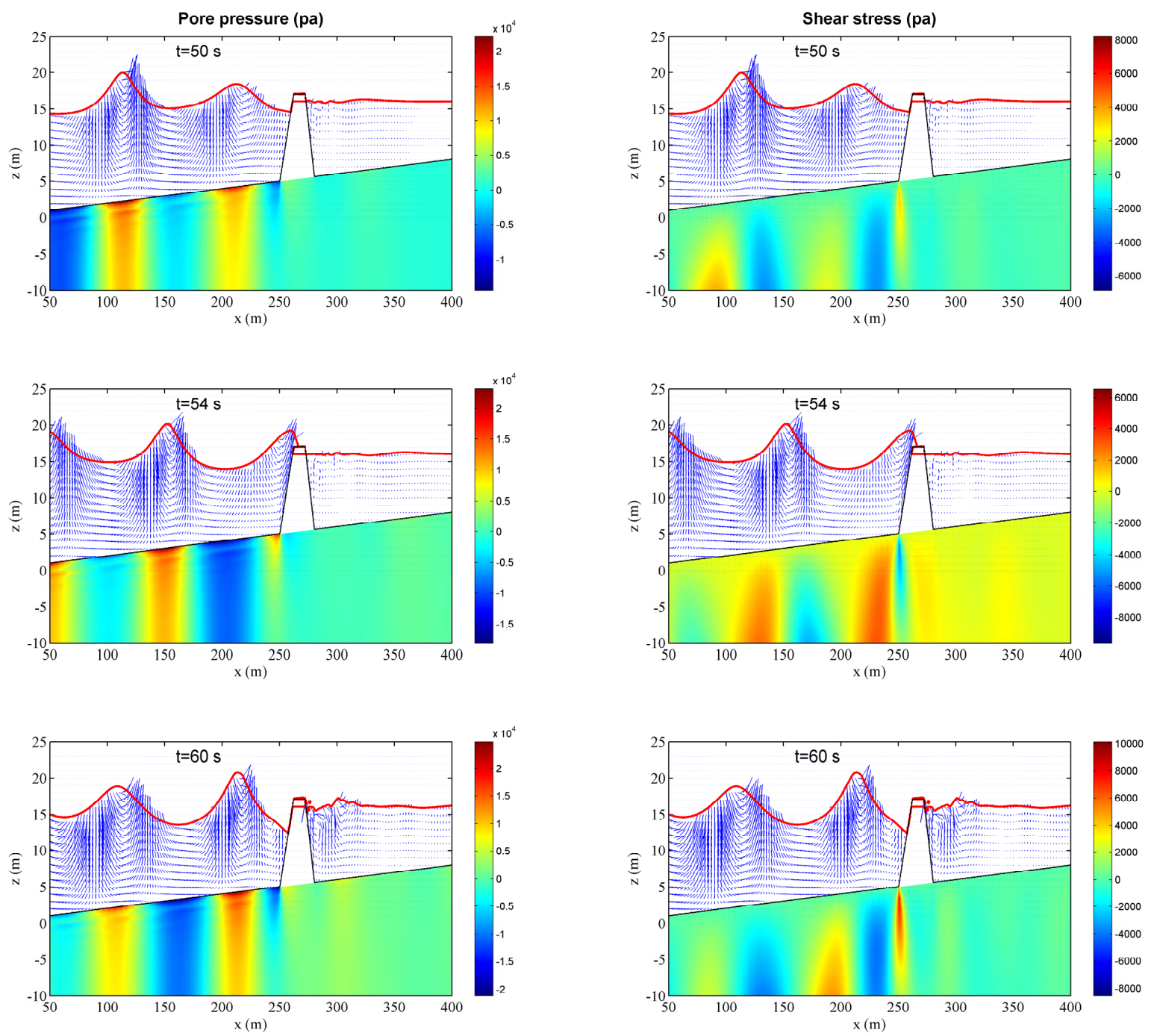

(a) oscillatory pore pressure $(\tilde{p})$

(b) oscillatory shear stress $(\tilde{\tau})$

Figure 7: Time histories of free surface elevation and the wave-induced oscillatory mechanisms including: (a) oscillatory pore pressure $(\tilde{p})$ and (b) oscillatory shear stress $(\tilde{\tau})$. 

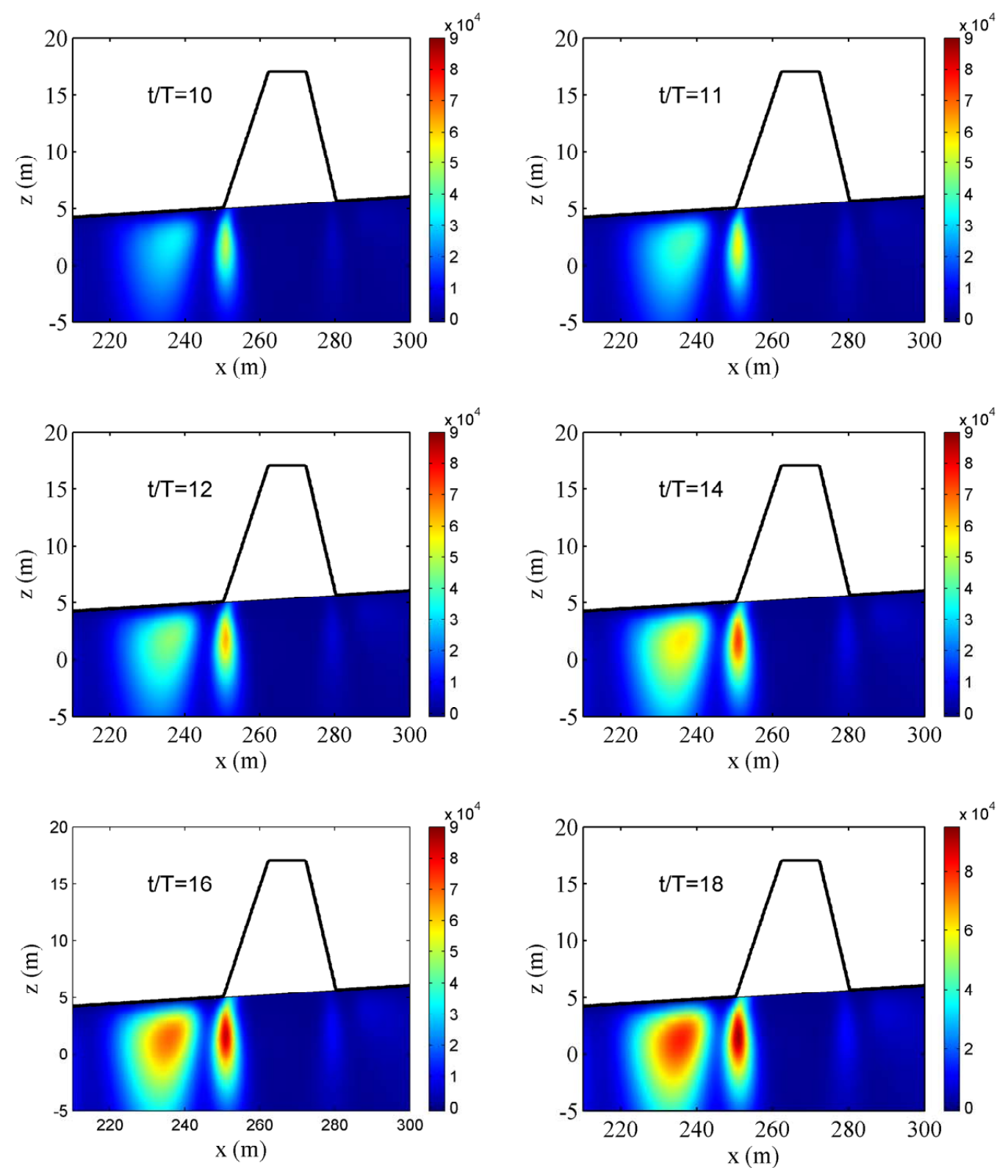

Figure 8: Patterns of wave-induced residual pore pressure $\left(\bar{p}_{s}\right)$ in the vicinity of breakwater at different wave cycle $t / T)$. 

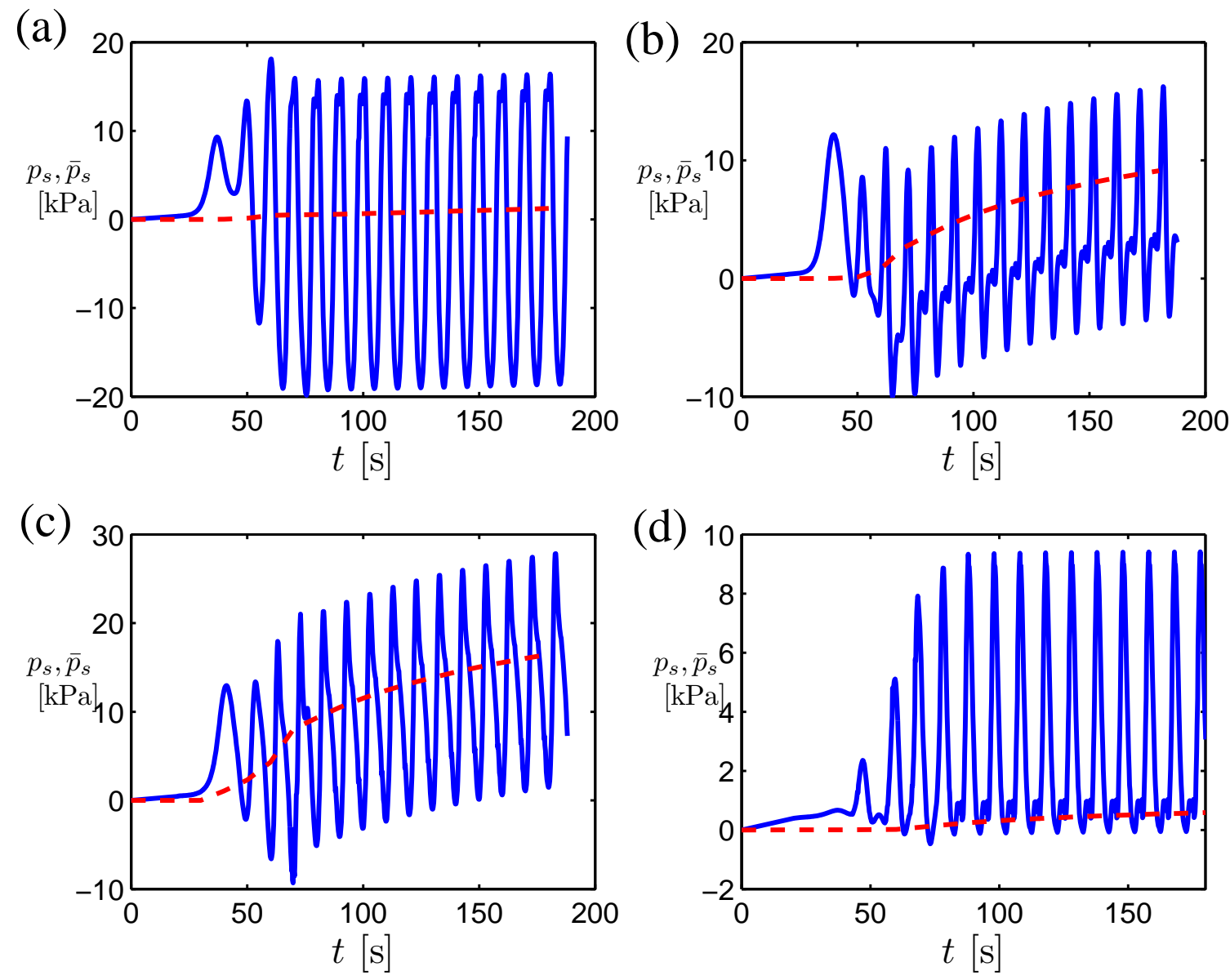

Figure 9: Wave-induced pore pressure buildup at four different locations. (a) $\mathrm{x}=215 \mathrm{~m}, \mathrm{z}=3.8 \mathrm{~m}$, (b) $\mathrm{x}=235 \mathrm{~m}$, $\mathrm{z}=4.2 \mathrm{~m}$, (c) $\mathrm{x}=250 \mathrm{~m}, \mathrm{z}=4.5 \mathrm{~m},(\mathrm{~d}) \mathrm{x}=300 \mathrm{~m}, \mathrm{z}=5.5 \mathrm{~m}$. Notation: soil lines represent pore pressure $\left(p_{s}\right)$; dashed lines represent residual pore pressure $\left(\bar{p}_{s}\right)$. 
(a)

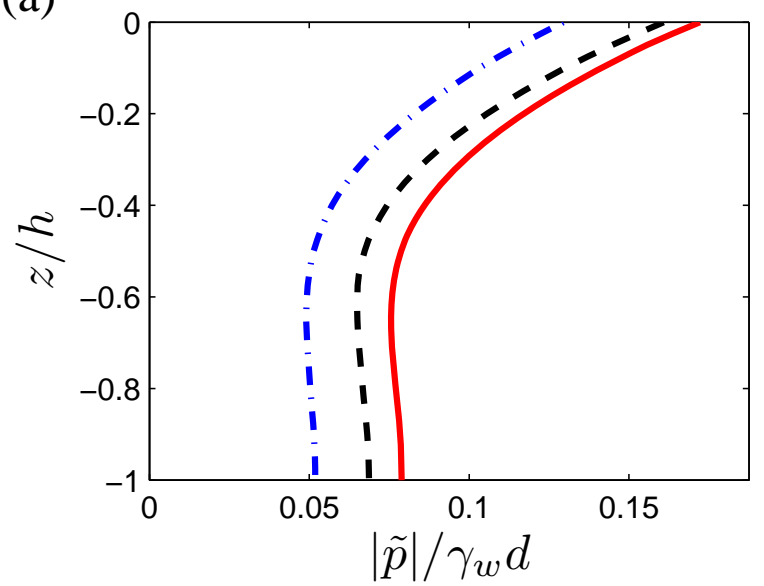

(c)

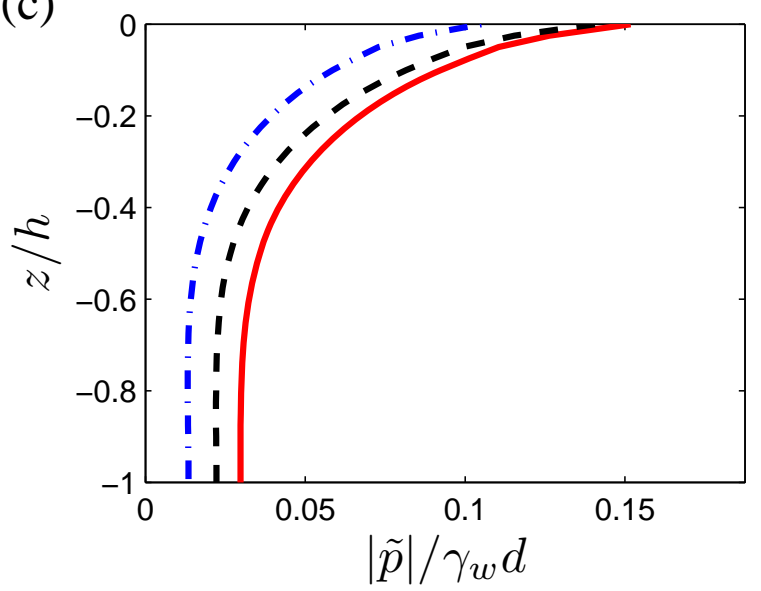

(b)

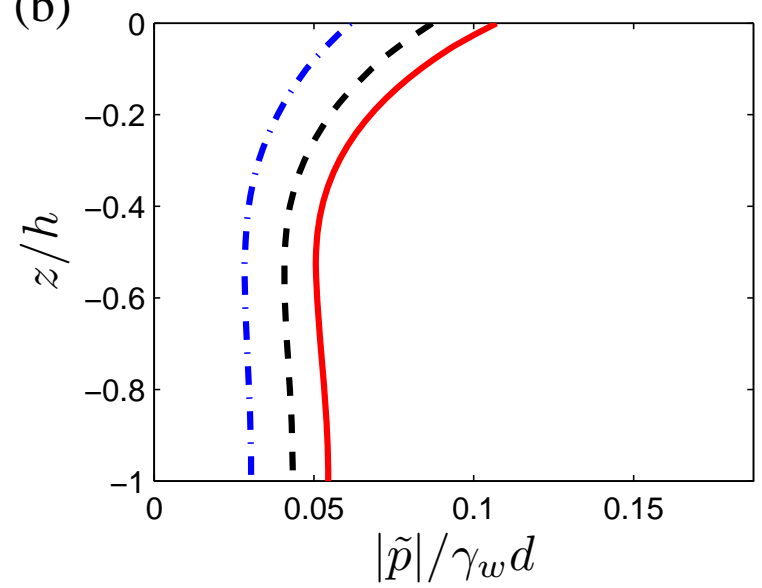

(d)

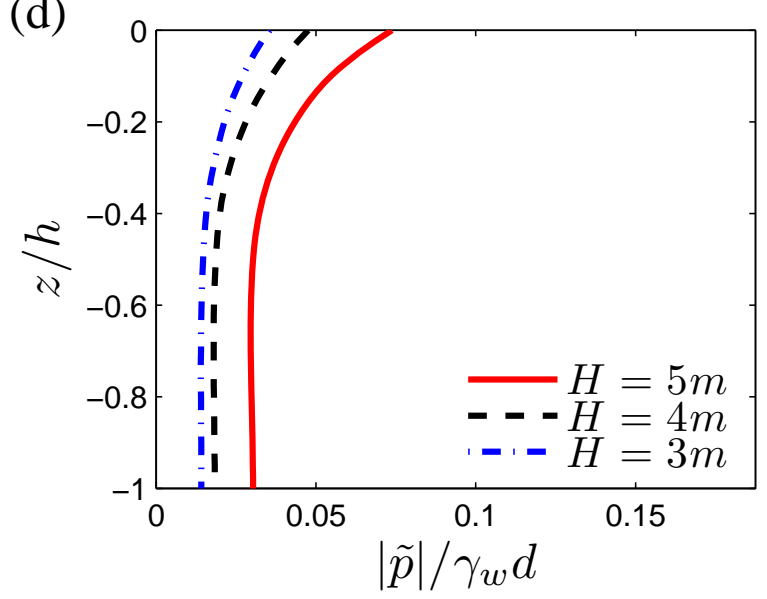

Figure 10: Vertical distributions of the wave-induced oscillatory pore pressure heads $\left(|\tilde{p}| / \gamma_{w} d\right)$ versus $z / h$ for various wave heights $(H)$ at four different locations in the vicinity of breakwater. (a) $\mathrm{x}=215 \mathrm{~m},(\mathrm{~b}) \mathrm{x}=235 \mathrm{~m}$, (c) $\mathrm{x}=250 \mathrm{~m},(\mathrm{~d}) \mathrm{x}=300 \mathrm{~m}$. 
(a)

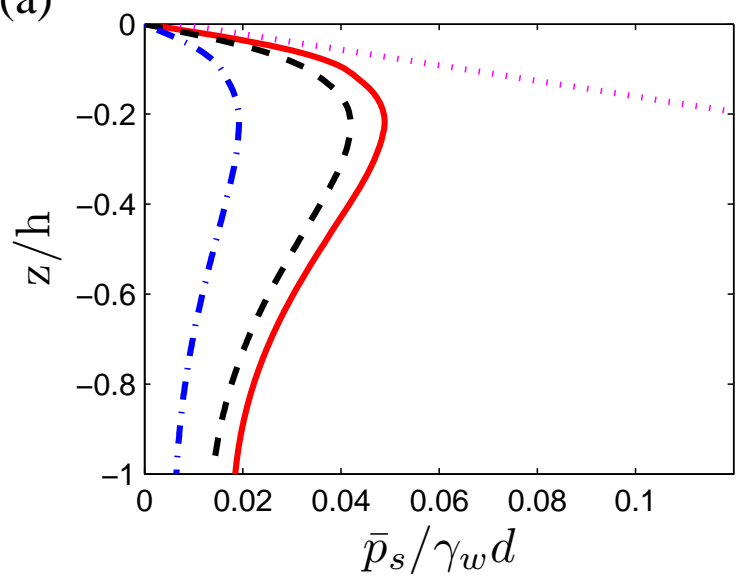

(c)

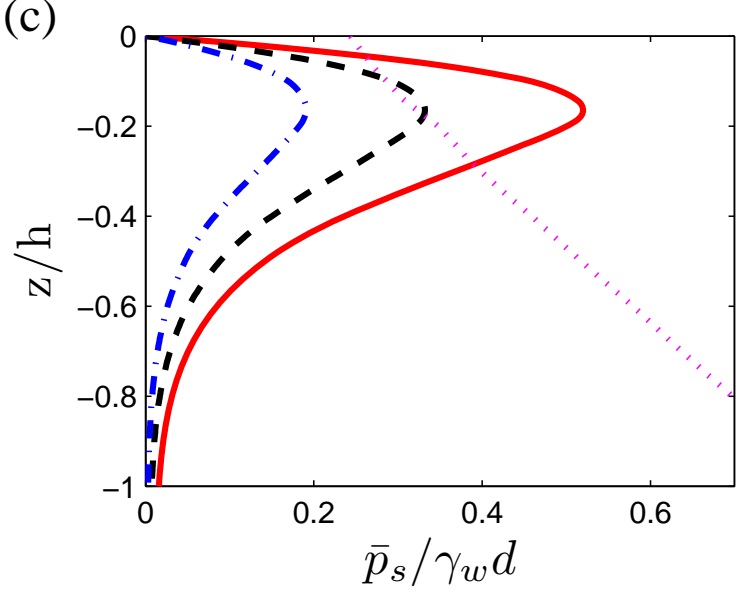

(b)

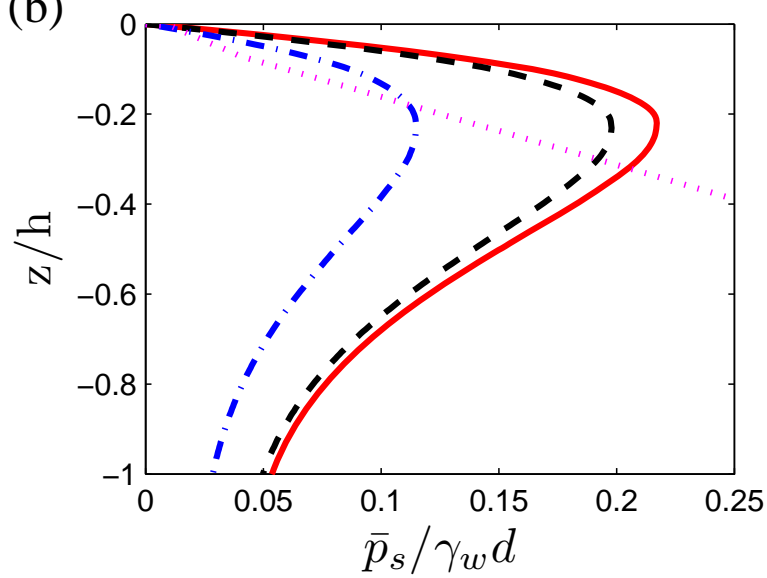

(d)

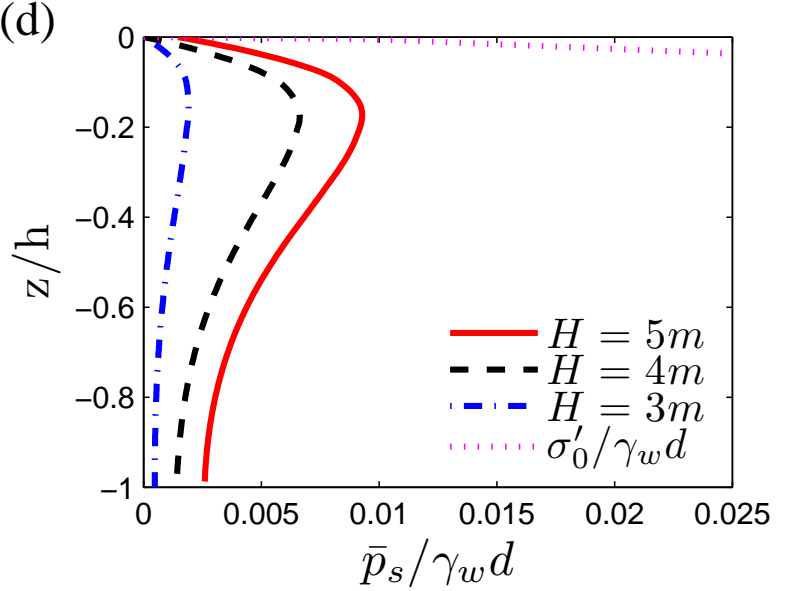

Figure 11: Vertical distributions of wave-induced residual pore pressure $\left(\bar{p} / \gamma_{w} d\right)$ for various wave heights $(H)$ at four different locations at $t / T=13$. (a) $\mathrm{x}=215 \mathrm{~m}$, (b) $\mathrm{x}=235 \mathrm{~m}$, (c) $\mathrm{x}=250 \mathrm{~m},(\mathrm{~d}) \mathrm{x}=300 \mathrm{~m}$. 

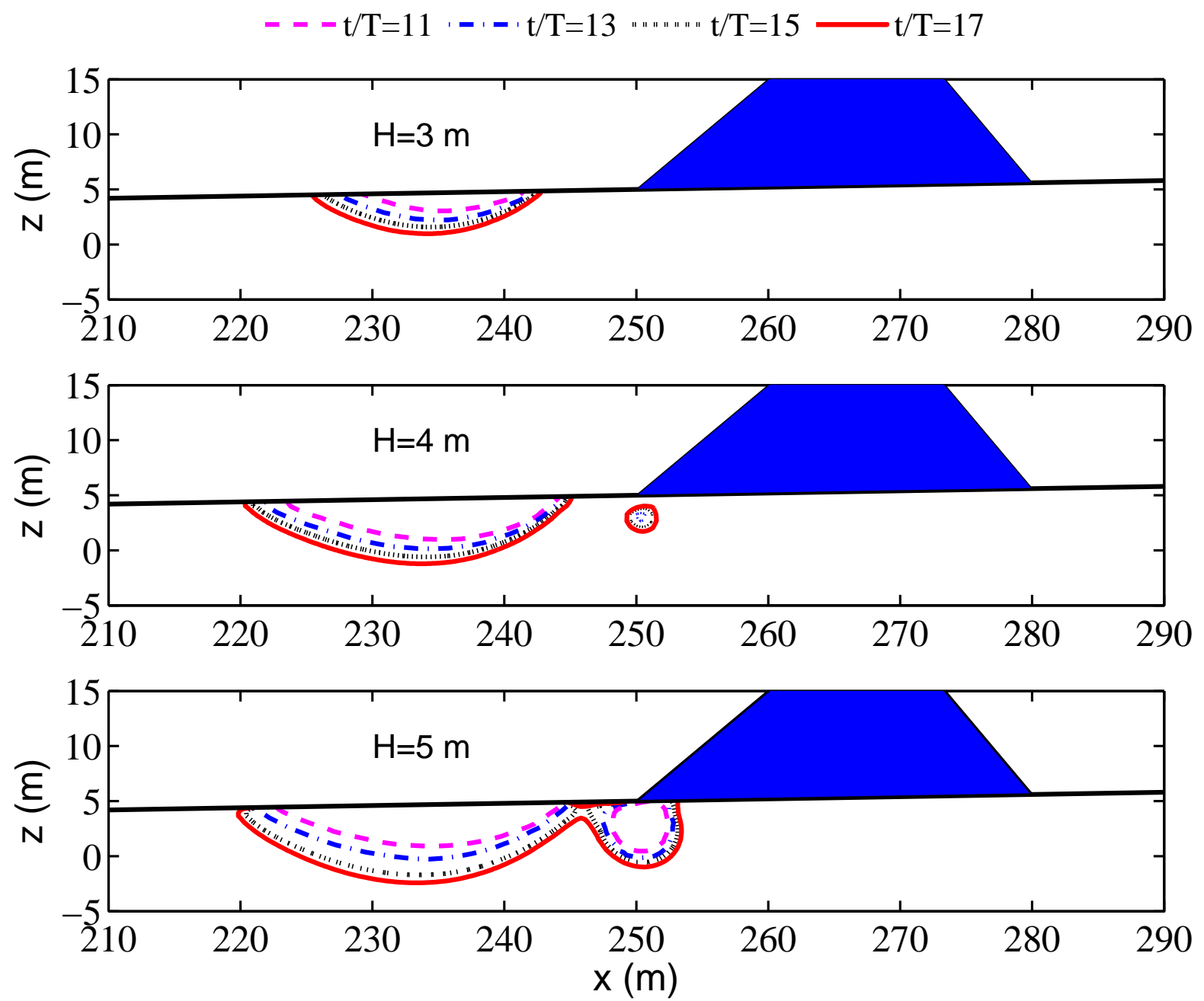

Figure 12: Development of liquefaction potential in the vicinity of breakwater with increasing wave cycle $(t / T)$ for the case with various wave heights $(H)$. 
(a)

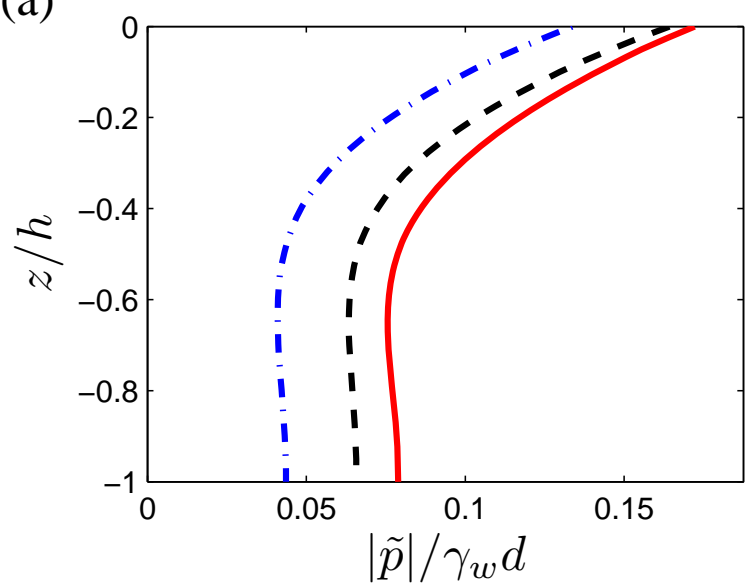

(c)

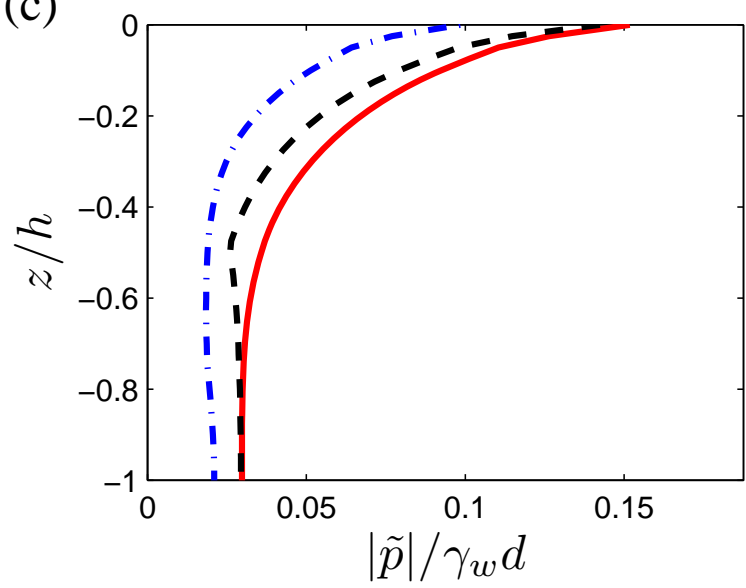

(b)

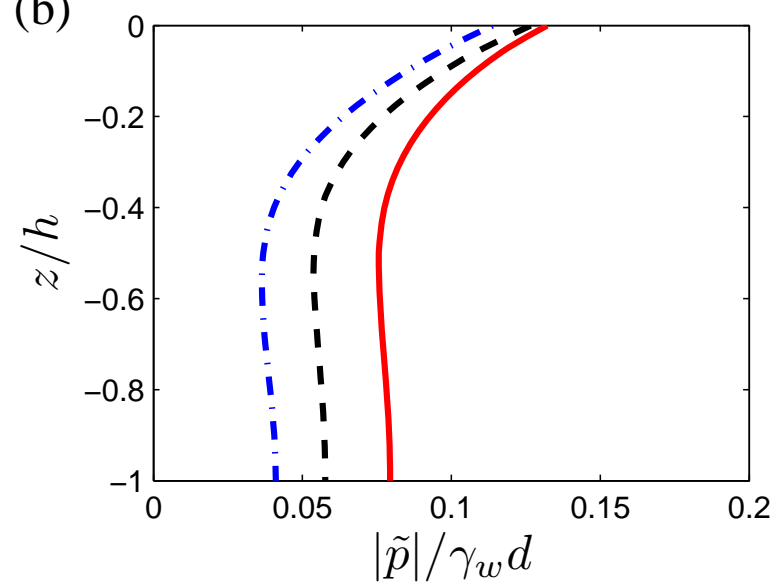

(d)

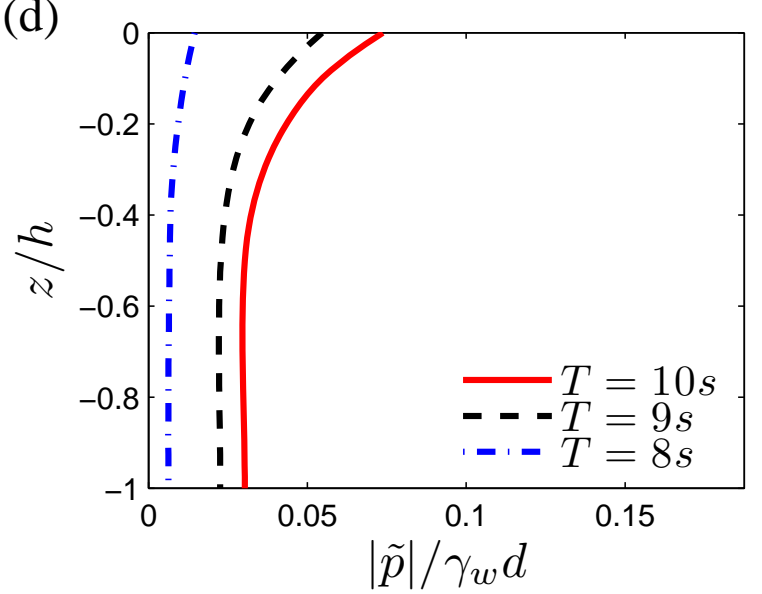

Figure 13: Vertical distributions of the wave-induced oscillatory pore pressure $\left(|\tilde{p}| / \gamma_{w} d\right)$ versus $z / h$ for various wave periods $(T)$ at four different locations in the vicinity of breakwater. (a) $\mathrm{x}=215 \mathrm{~m}$, (b) $\mathrm{x}=235 \mathrm{~m}$, (c) $\mathrm{x}=250 \mathrm{~m}$, (d) $\mathrm{x}=300 \mathrm{~m}$. 
(a)

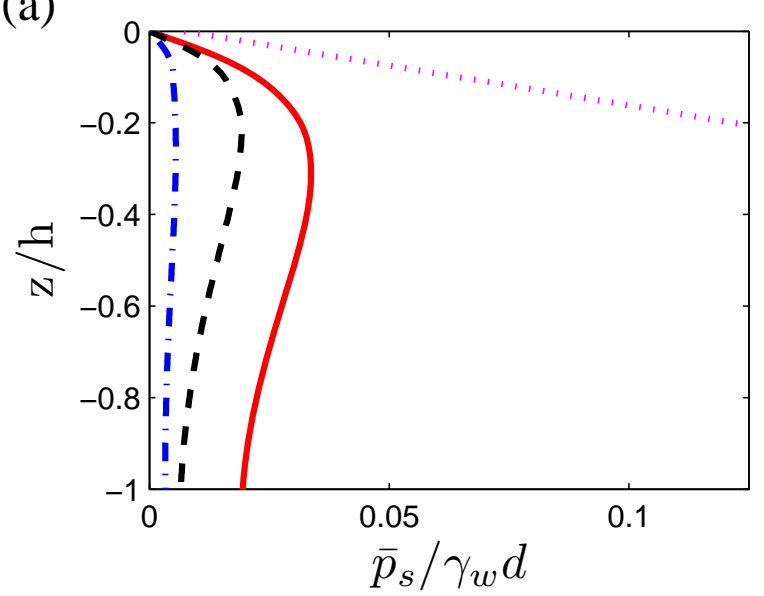

(c)

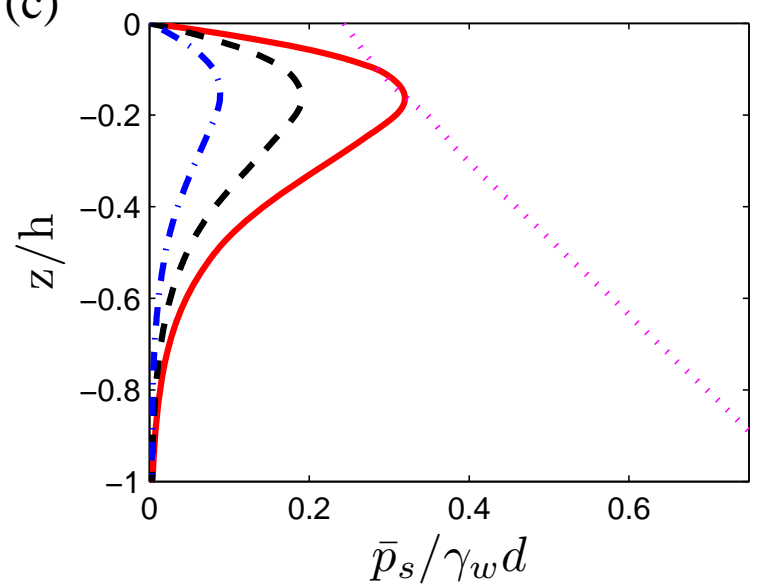

(b)

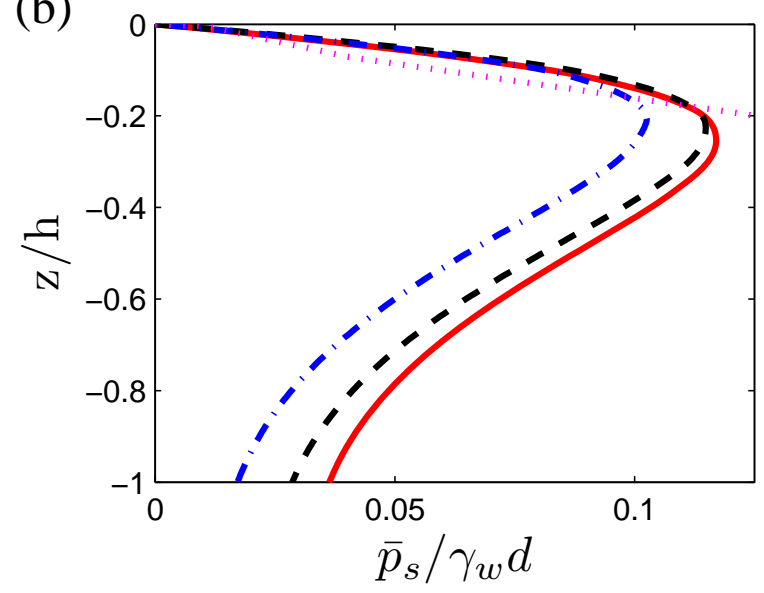

(d)

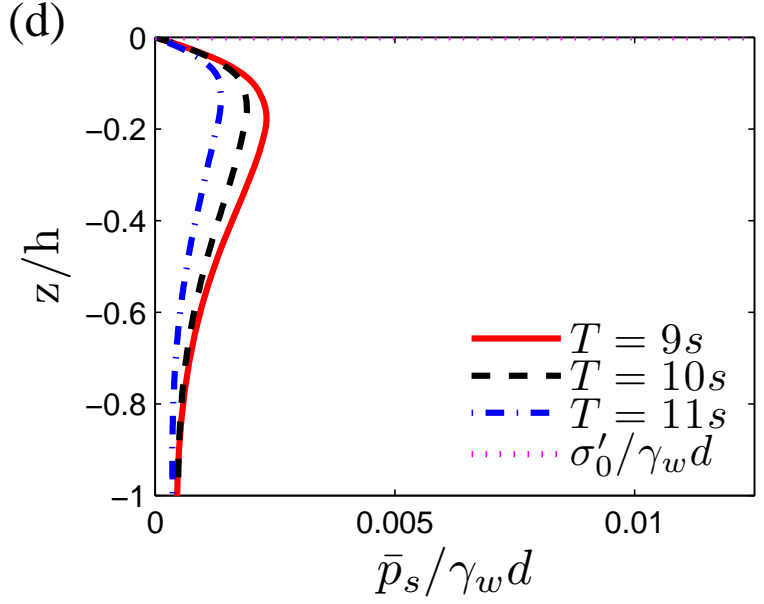

Figure 14: Vertical distributions of wave-induced residual pore pressure $\left(\bar{p} / \gamma_{w} d\right)$ for various wave periods $(T)$ at four different locations at $t / T=13$. (a) $\mathrm{x}=215 \mathrm{~m}$, (b) $\mathrm{x}=235 \mathrm{~m}$, (c) $\mathrm{x}=250 \mathrm{~m}$, (d) $\mathrm{x}=300 \mathrm{~m}$. 

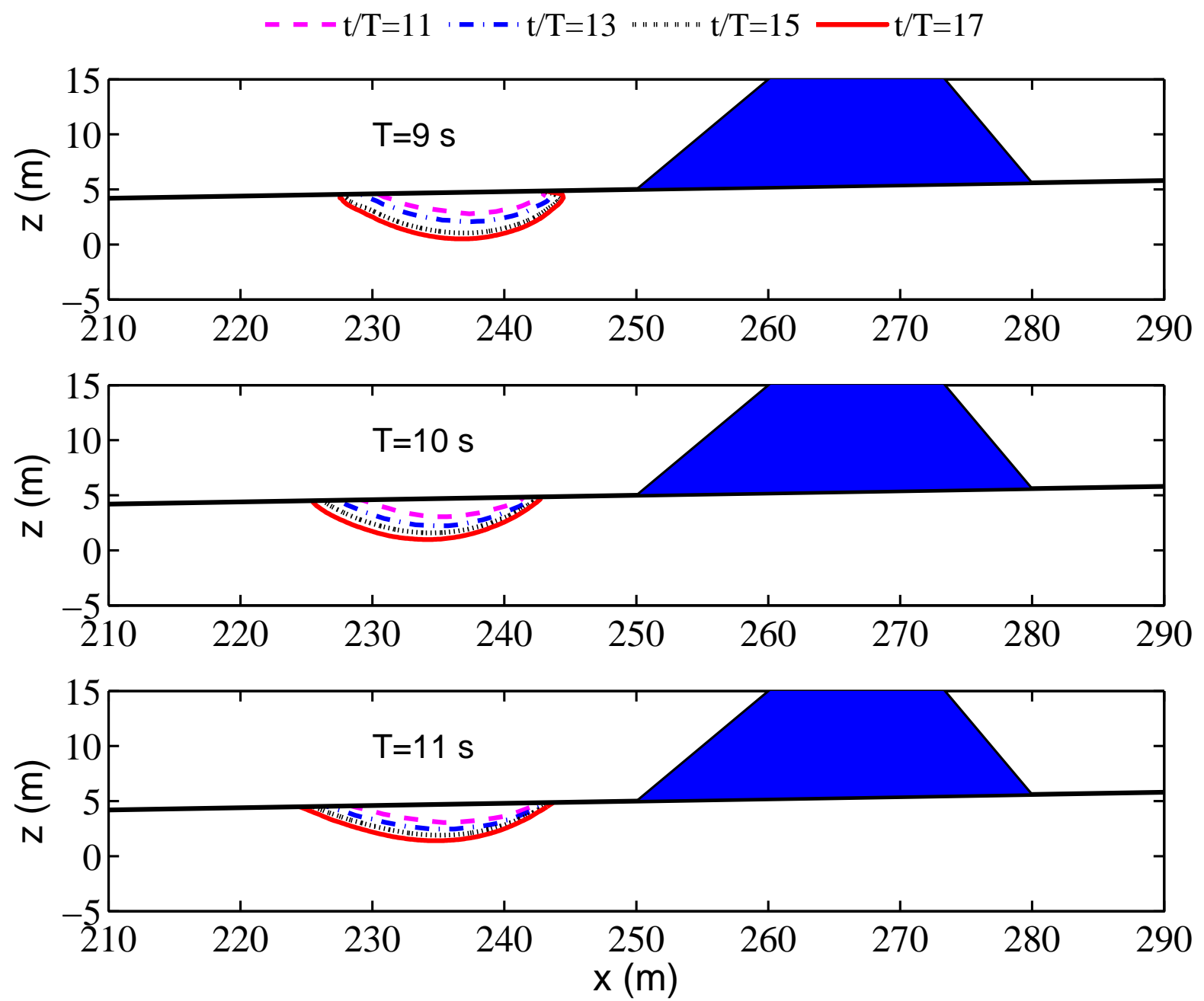

Figure 15: Development of liquefaction potential in the vicinity of breakwater with increasing wave cycle $(t / T)$ for the case with various wave periods $(T)$. 
(a)

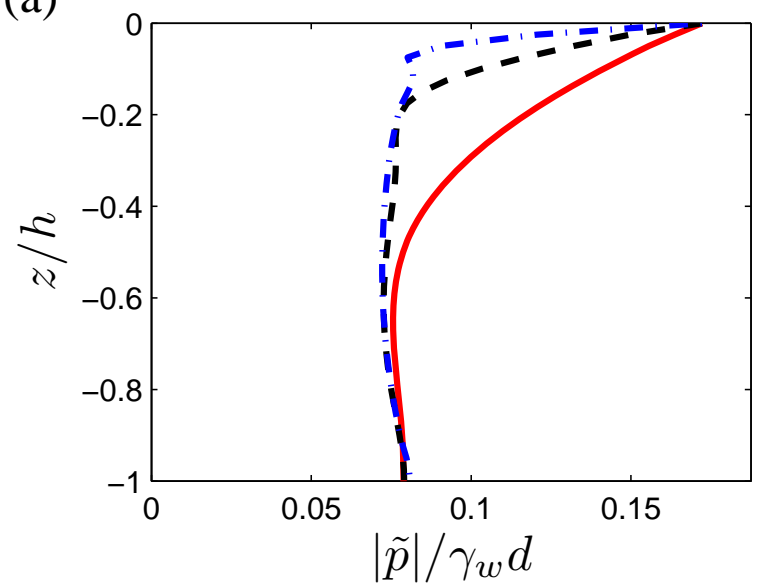

(c)

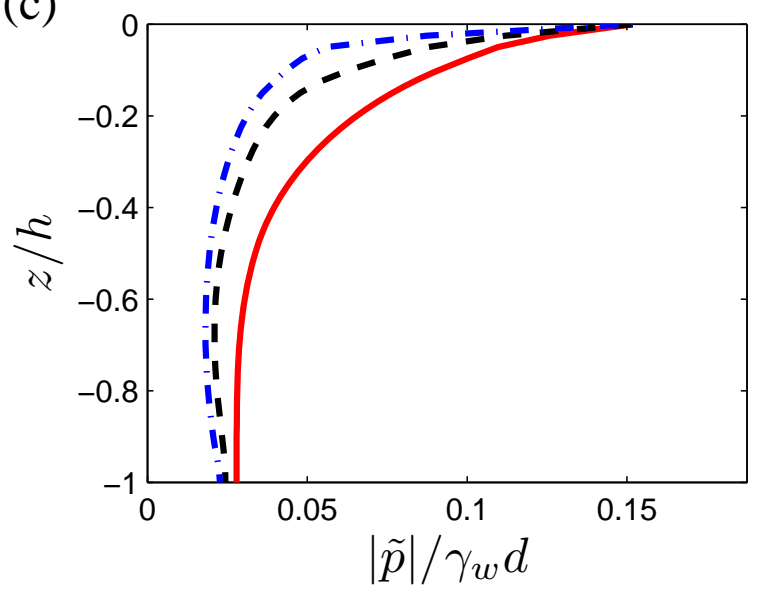

(b)

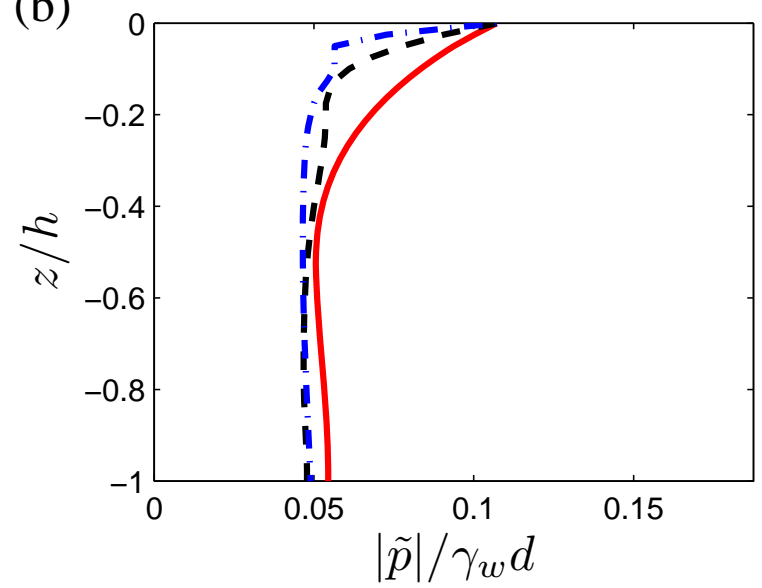

(d)

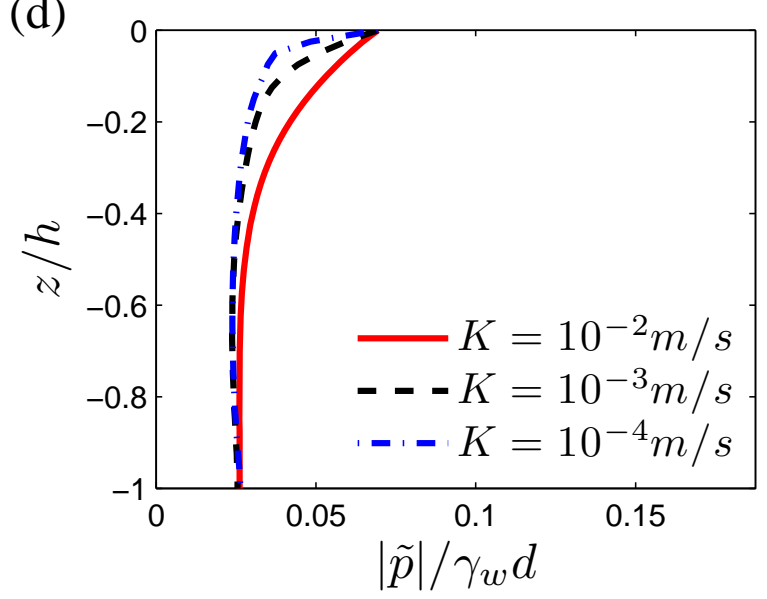

Figure 16: Vertical distributions of the wave-induced oscillatory pore pressure $\left(|\tilde{p}| / \gamma_{w} d\right)$ versus $z / h$ for various permeability of soil $(K)$ at four different locations in the vicinity of breakwater. (a) $\mathrm{x}=215 \mathrm{~m}$, (b) $\mathrm{x}=235 \mathrm{~m}$, (c) $\mathrm{x}=250 \mathrm{~m},(\mathrm{~d}) \mathrm{x}=300 \mathrm{~m}$. 

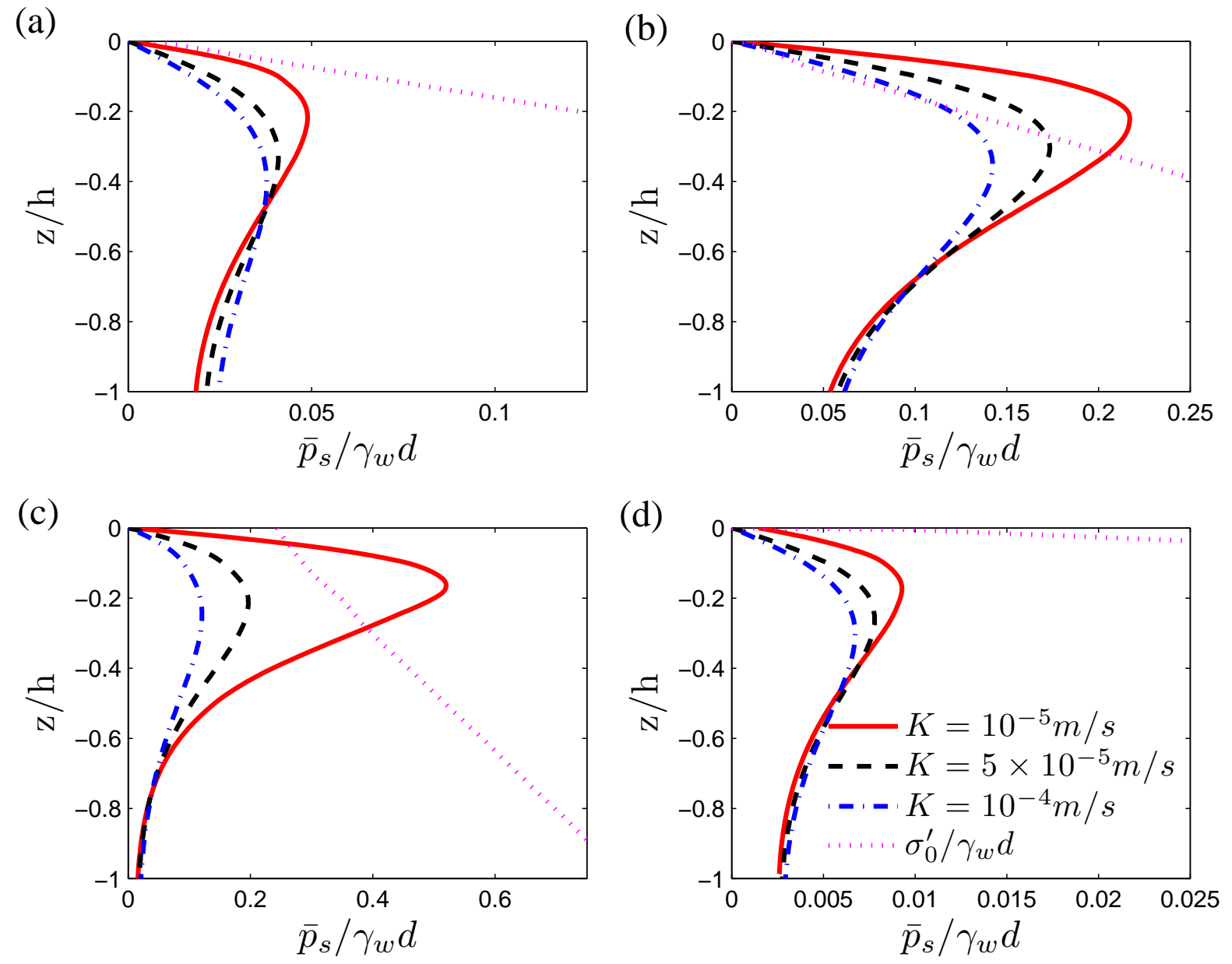

Figure 17: Vertical distributions of wave-induced residual pore pressure $\left(\bar{p} / \gamma_{w} d\right)$ for various permeability of soil $(K)$ at four different locations at $t / T=13$. (a) $\mathrm{x}=215 \mathrm{~m}$, (b) $\mathrm{x}=235 \mathrm{~m}$, (c) $\mathrm{x}=250 \mathrm{~m}$, (d) $\mathrm{x}=300 \mathrm{~m}$. 

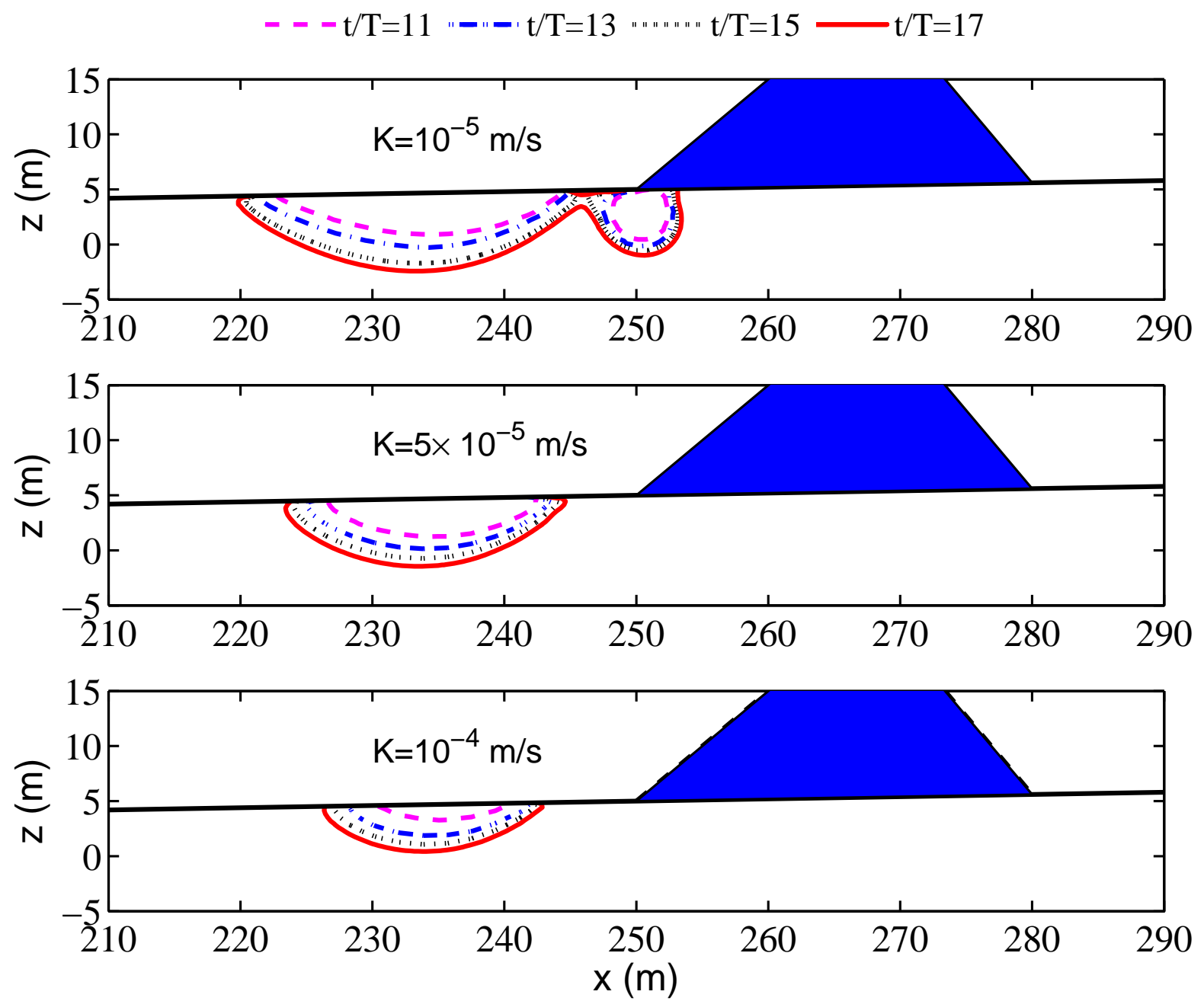

Figure 18: Development of liquefaction potential in the vicinity of breakwater with increasing wave cycle $(t / T)$ for the case with various permeability of soil $(K)$. 

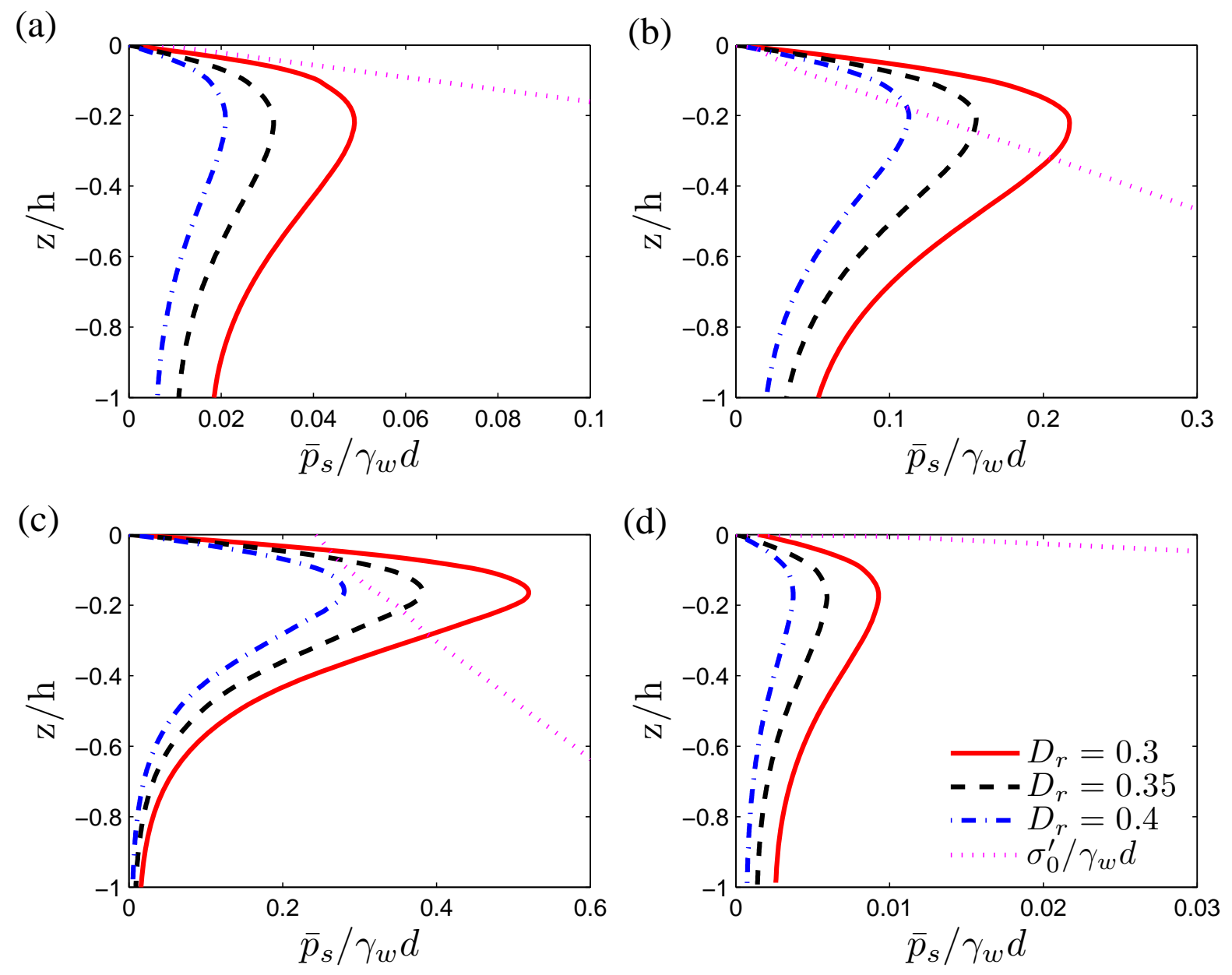

Figure 19: Vertical distributions of wave-induced residual pore pressure $\left(\bar{p} / \gamma_{w} d\right)$ for various relative density of soil $\left(D_{r}\right)$ at four different locations at $t / T=13$. (a) $\mathrm{x}=215 \mathrm{~m}$, (b) $\mathrm{x}=235 \mathrm{~m}$, (c) $\mathrm{x}=250 \mathrm{~m}$, (d) $\mathrm{x}=300 \mathrm{~m}$. 

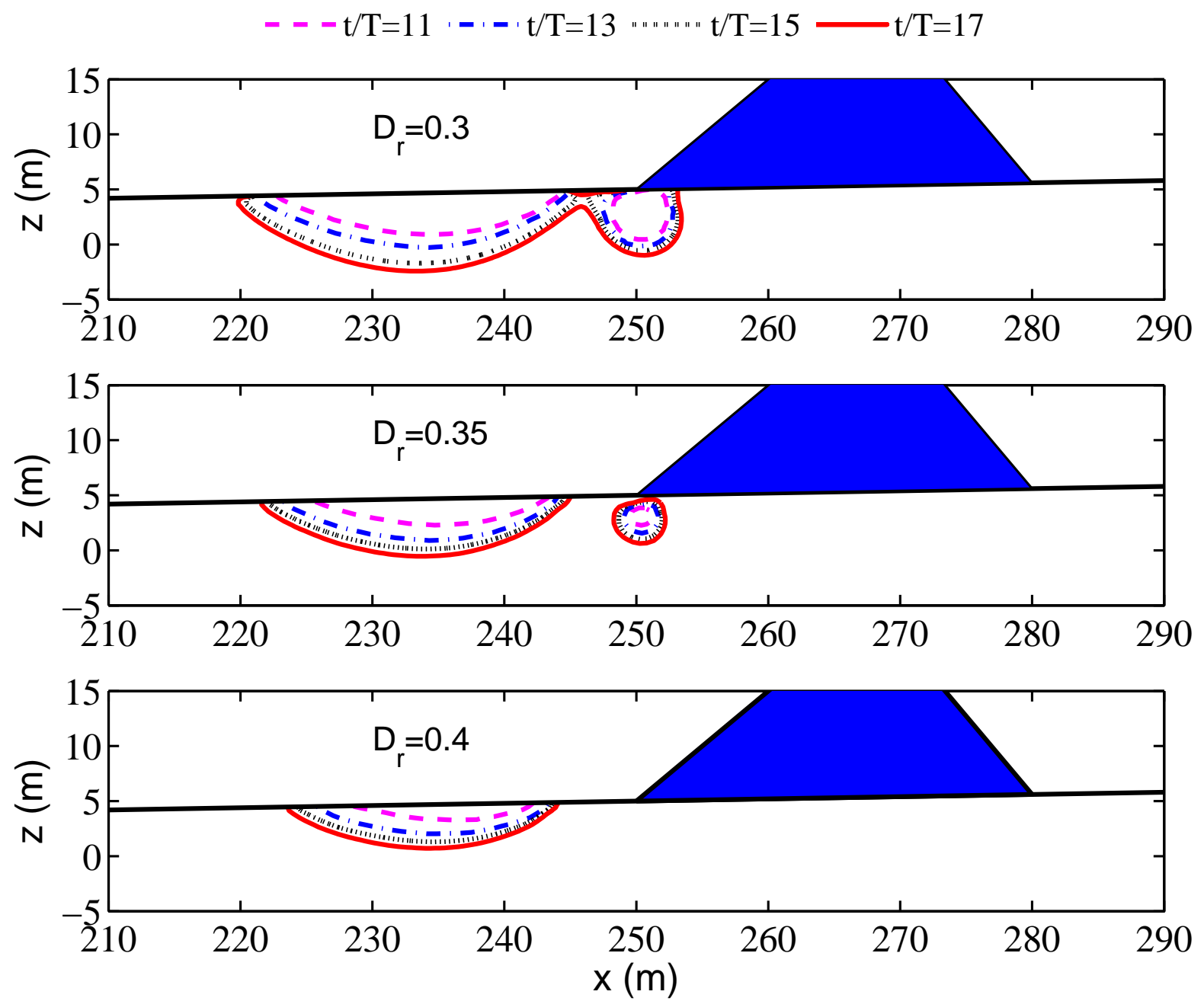

Figure 20: Development of liquefaction potential in the vicinity of breakwater with increasing wave cycle $(t / T)$ for the case with various relative density of soil $\left(D_{r}\right)$. 


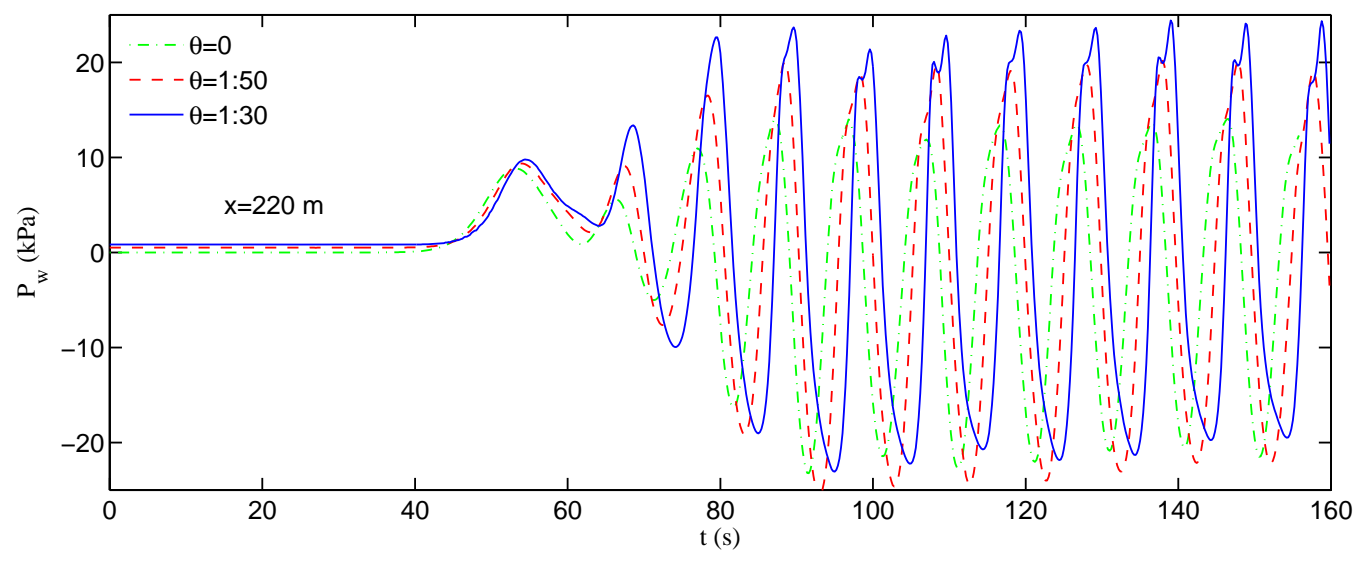

Figure 21: Variation of hydro-dynamic pressure acting at a typical point of sloping seabed with various bed slopes $(\theta)$. 
(a)

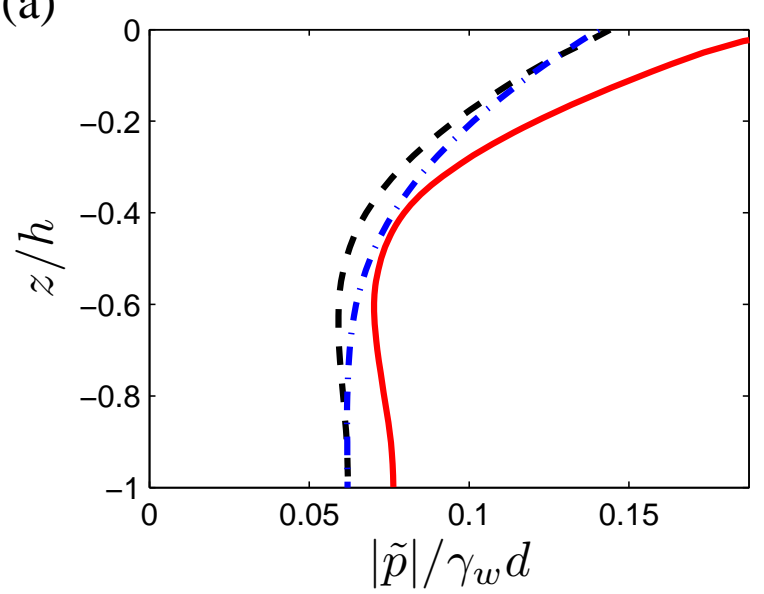

(c)

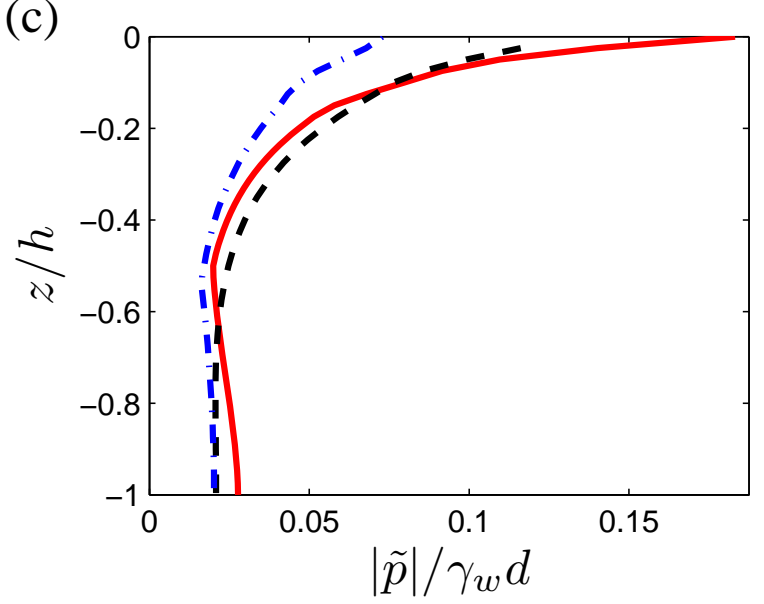

(b)

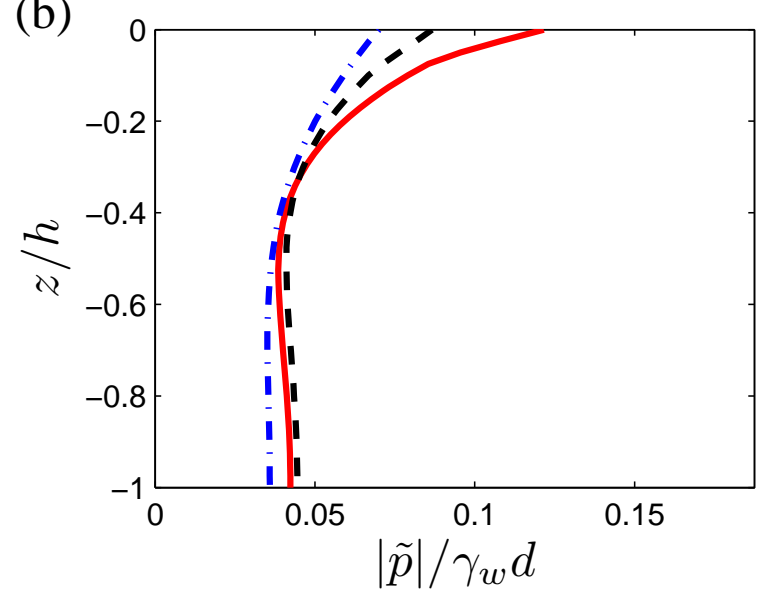

(d)

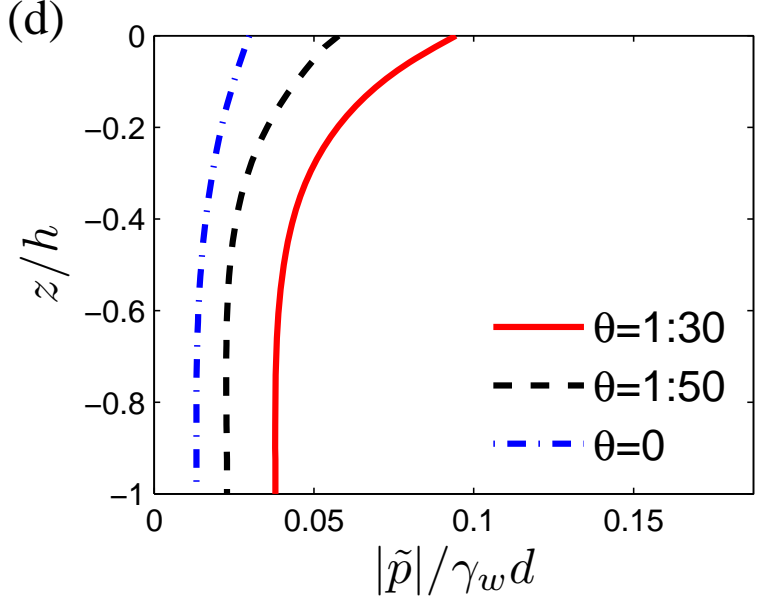

Figure 22: Vertical distributions of the wave-induced oscillatory pore pressure $\left(|\tilde{p}| / \gamma_{w} d\right)$ versus $z / h$ at four different locations in the sloping seabed with various bed slopes $(\theta)$. (a) $x=215 \mathrm{~m}$, (b) $\mathrm{x}=235 \mathrm{~m}$, (c) $\mathrm{x}=250 \mathrm{~m}$, (d) $\mathrm{x}=300 \mathrm{~m}$. 
(a)

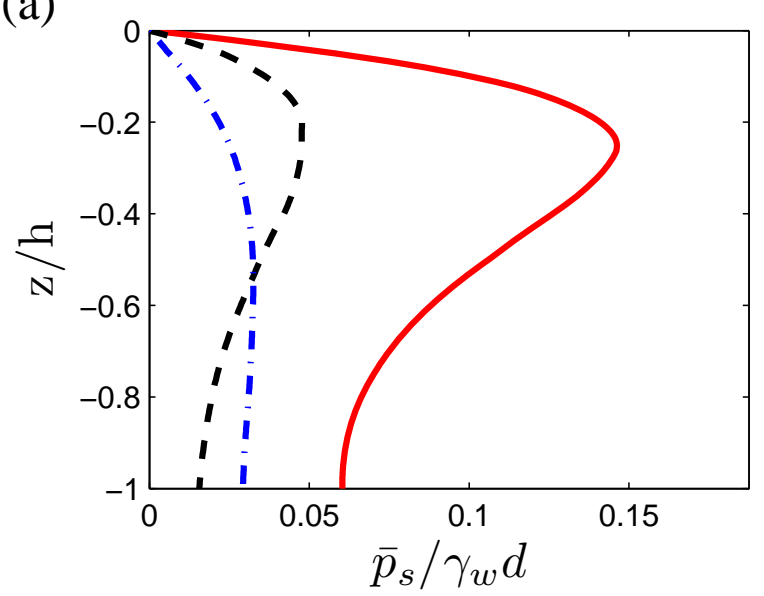

(c)

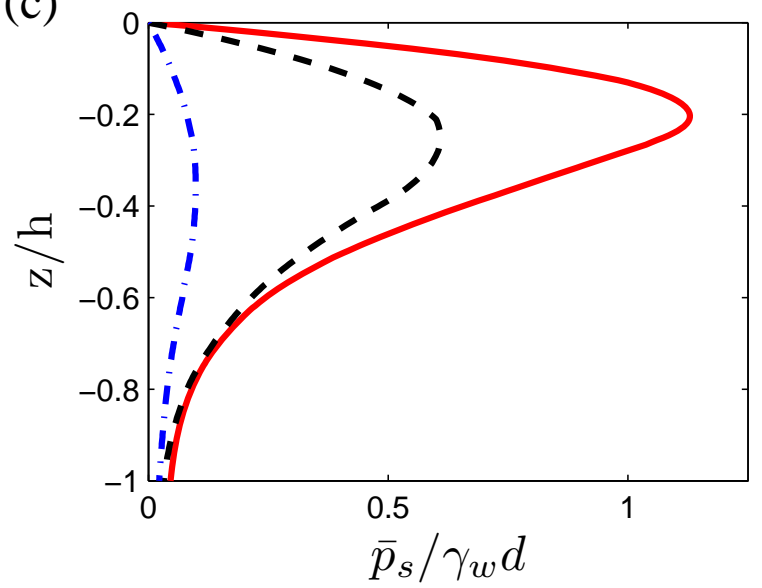

(b)

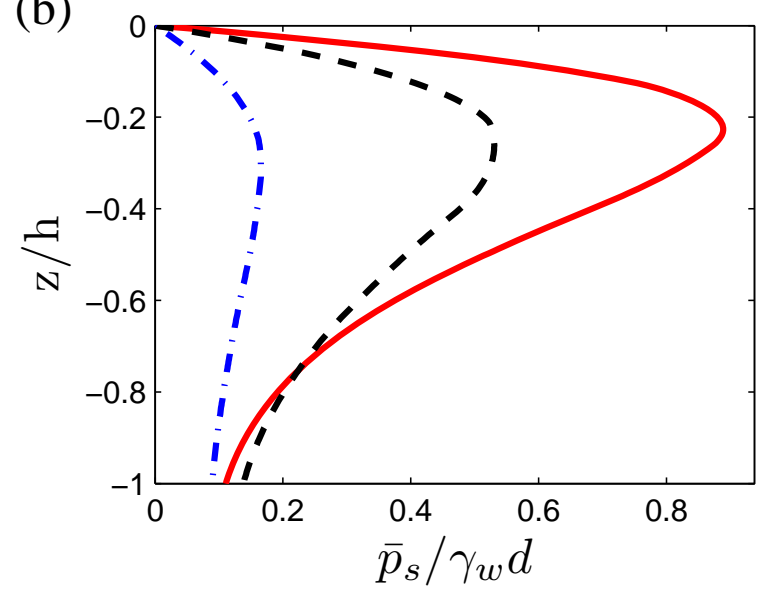

(d)

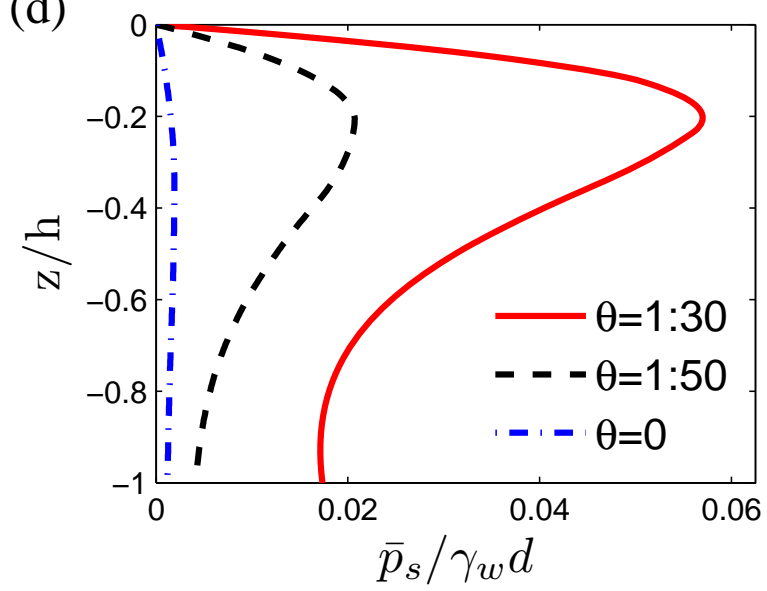

Figure 23: Vertical distributions of wave-induced residual pore pressure $\left(\bar{p} / \gamma_{w} d\right)$ at four different locations of sloping seabed with various bed slopes $(\theta)(\theta)$ at $t / T=20$. (a) $x=215 \mathrm{~m}$, (b) $\mathrm{x}=235 \mathrm{~m}$, (c) $\mathrm{x}=250 \mathrm{~m}$, (d) $\mathrm{x}=300 \mathrm{~m}$. 

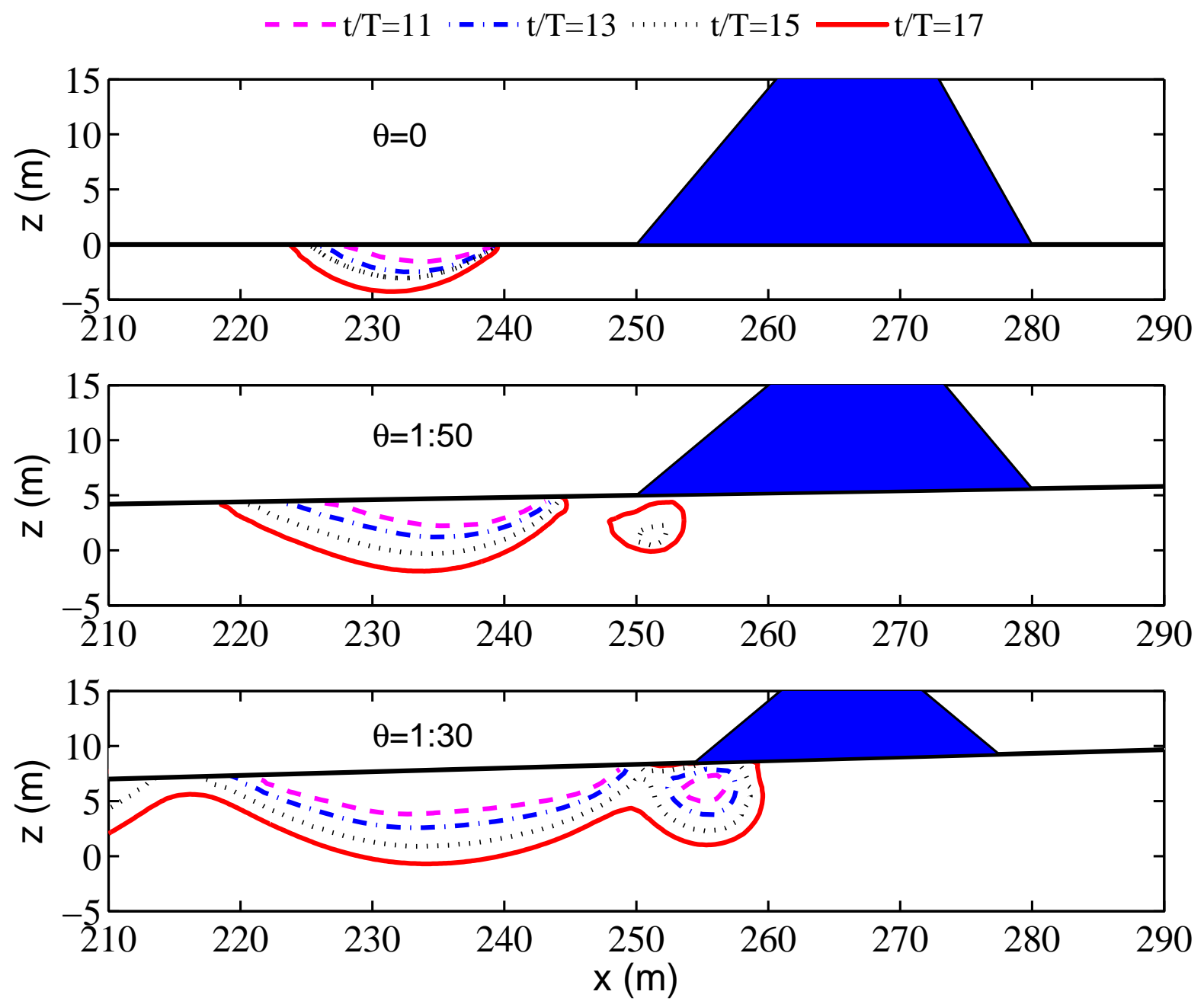

Figure 24: Development of liquefaction potential in the vicinity of breakwater with increasing wave cycle $(t / T)$ for the case with various bed slopes $(\theta)$. 
(a)

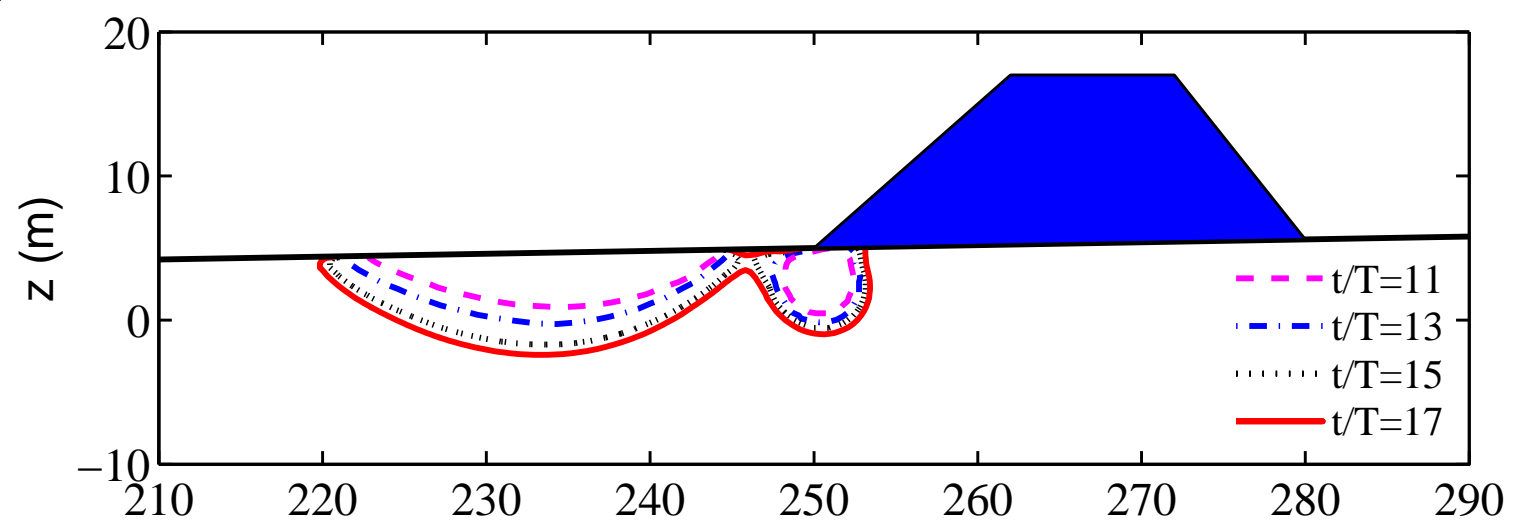

(b)

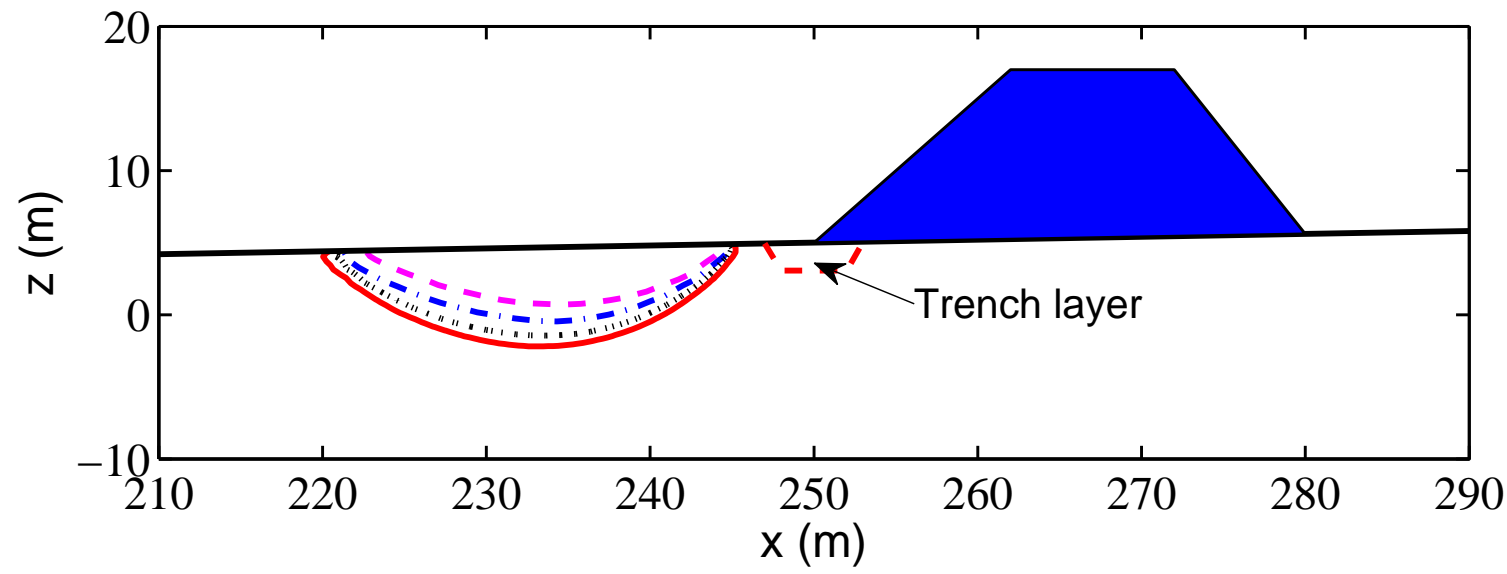

Figure 25: Effect of a cover layer on the development of liquefaction potential in the vicinity of the breakwater (a) without a cover layer; and (b) with a cover layer. 

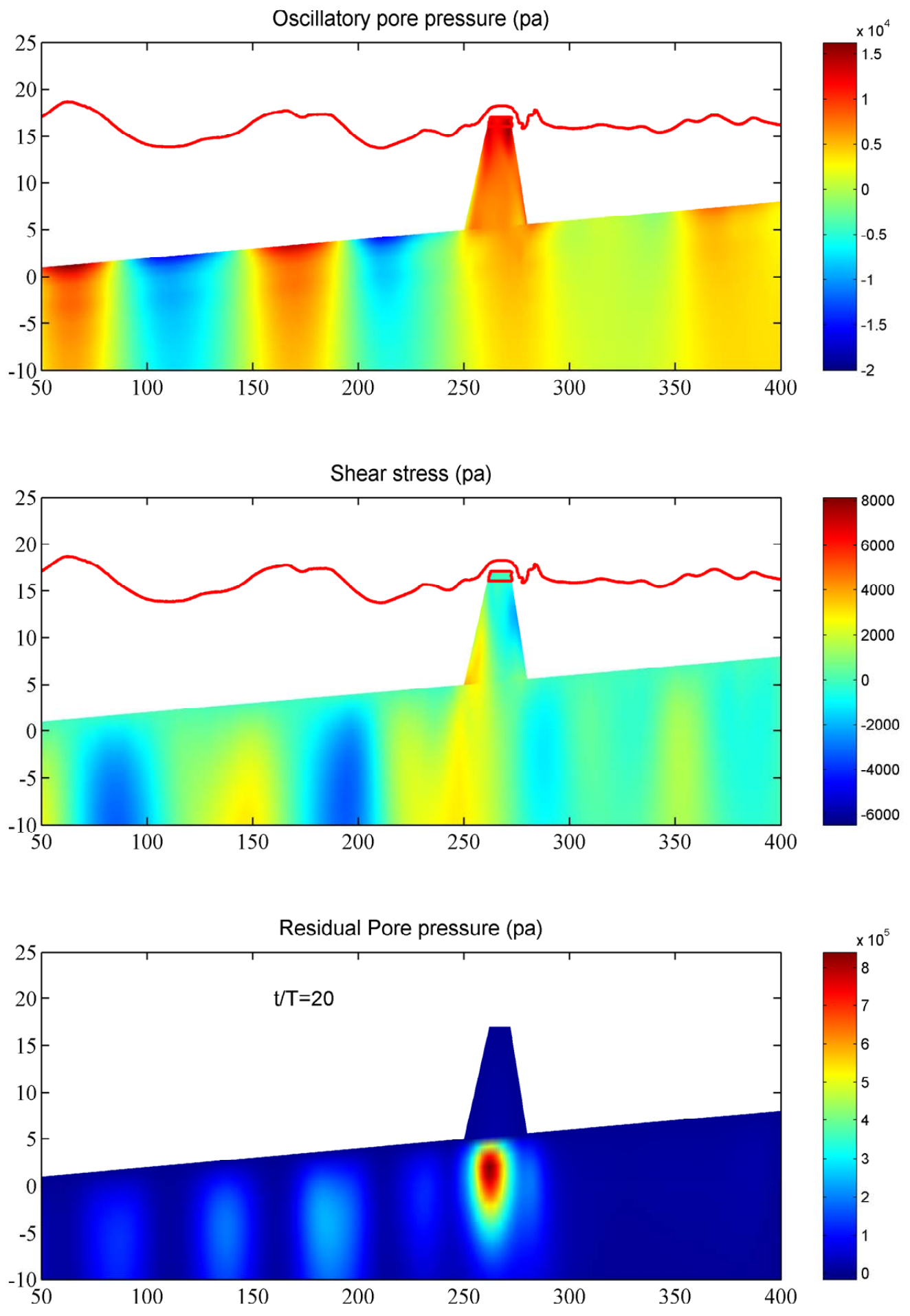

Figure 26: Distribution of wave-induced pore pressure and shear stress in the vicinity of a rubble mound breakwater. 
(a)

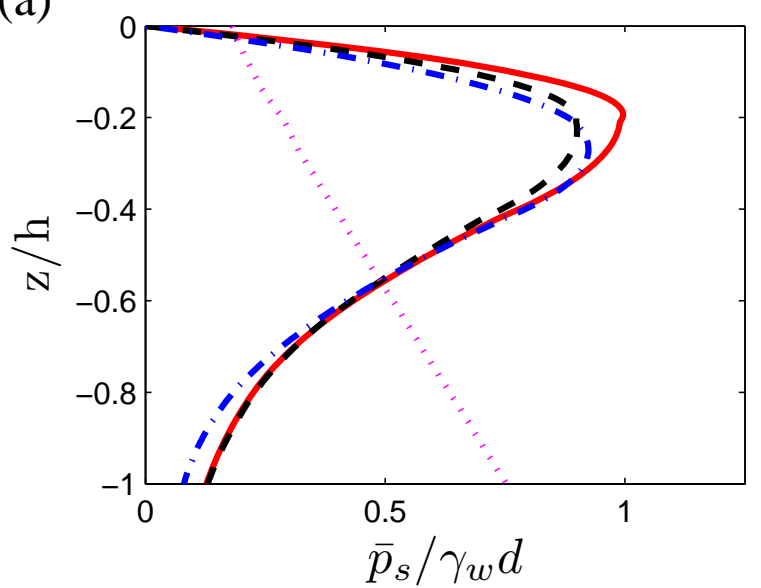

(c)

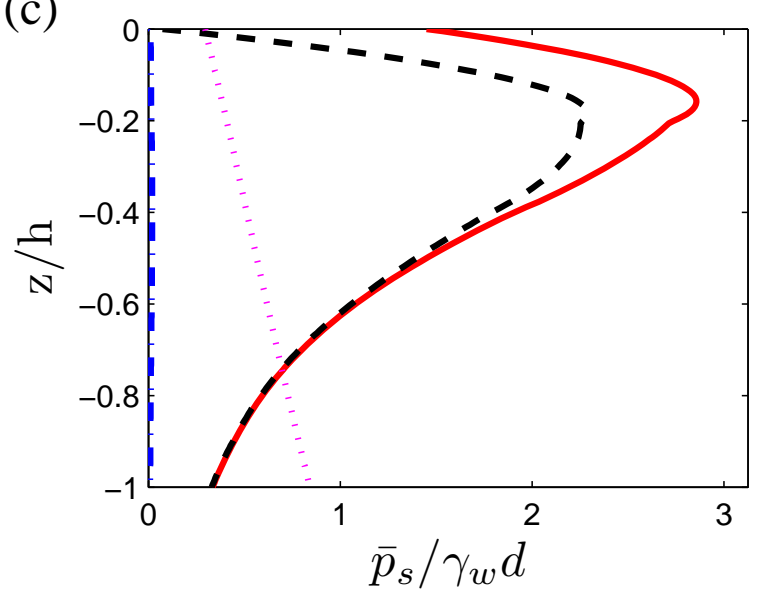

(b)

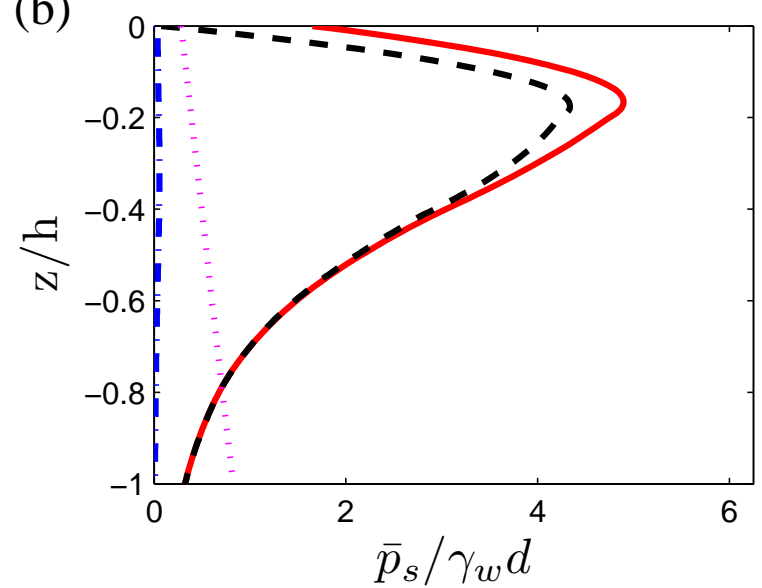

(d)

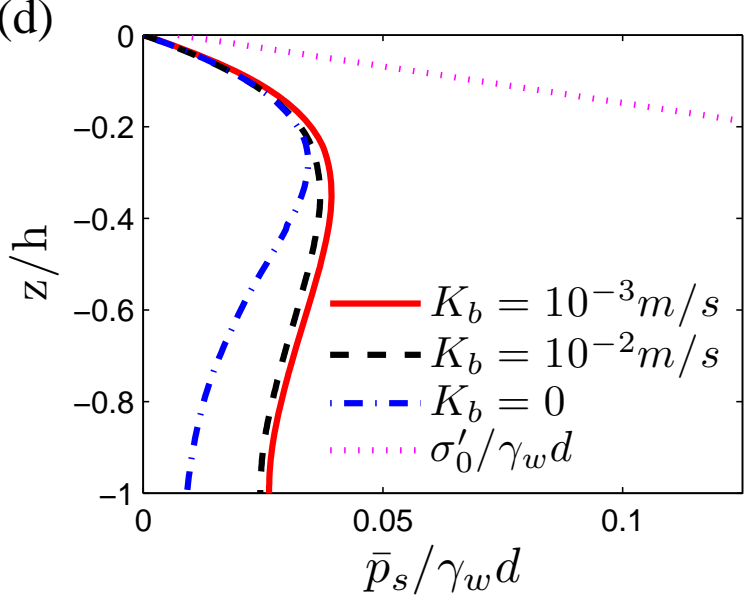

Figure 27: Vertical distributions of wave-induced residual pore pressure $\left(\bar{p} / \gamma_{w} d\right)$ at four different locations in the vicinity of the breakwater with various permeability $\left(K_{b}\right)$ at $t / T=20$. (a) $\mathrm{x}=250 \mathrm{~m}$, (b) $\mathrm{x}=260 \mathrm{~m}$, (c) $\mathrm{x}=270 \mathrm{~m},(\mathrm{~d})$ $\mathrm{x}=300 \mathrm{~m}$. 

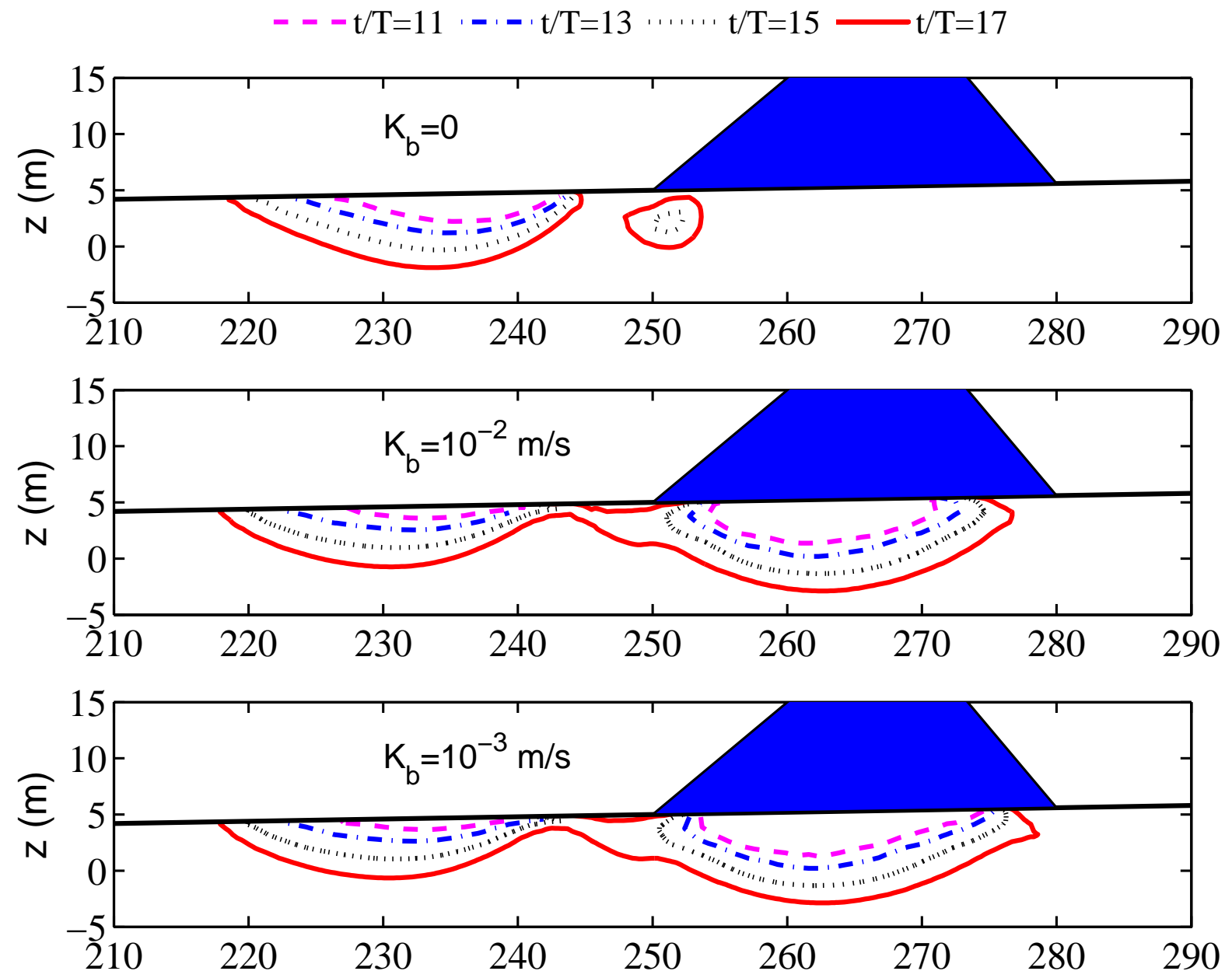

Figure 28: Development of liquefaction potential with increasing wave cycle $(t / T)$ in the vicinity of breakwater with various permeability $\left(K_{b}\right)$. 